Review

\title{
Plant-based Food Products for Antimycobacterial Therapy
}

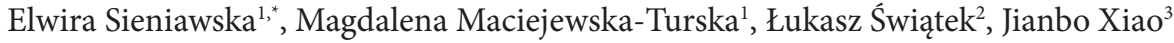 \\ ${ }^{1}$ Department of Pharmacognosy, Medical University of Lublin, Lublin, Poland \\ ${ }^{2}$ Department of Virology, Medical University of Lublin, Lublin, Poland \\ ${ }^{3}$ Institute of Chinese Medical Sciences, University of Macau, Macau, Macao, China
}

\section{ARTICLE INFO}

\section{Article History}

Received 02 January 2020

Accepted 15 April 2020

\section{Keywords}

Immunity

hepatoprotection

Mycobacterium tuberculosis

diet supplementation

\begin{abstract}
Traditional medicine which is based on the observations of the patient's condition after administration of herbal remedies describes a vast number of plant species with potential application in Tuberculosis (TB) treatment. However, only a small number of plant derived secondary metabolites were shown to influence Mycobacterium tuberculosis (Mtb) in mico- or nanomolar concentrations. Nevertheless, plant-based food products were proven to be useful in tuberculosis treatment, including eradication of Mtb, boosting natural immunity, managing disease symptoms and side effects of tuberculostatic drugs, as well as providing proper nutrition and diet supplementation. This review describes natural products, with a focus on plant-based food products, useful in antimycobacterial therapy. It summarizes the antituberculous potential of ethnopharmacologically selected medicinal plants, herbs, spices and fruits. Moreover, the use of plant-based food products as supportive treatment of TB therapy is discussed. Proper diet supplementation in tuberculosis treatment is also considered.
\end{abstract}

\section{GRAPHICAL ABSTRACT}
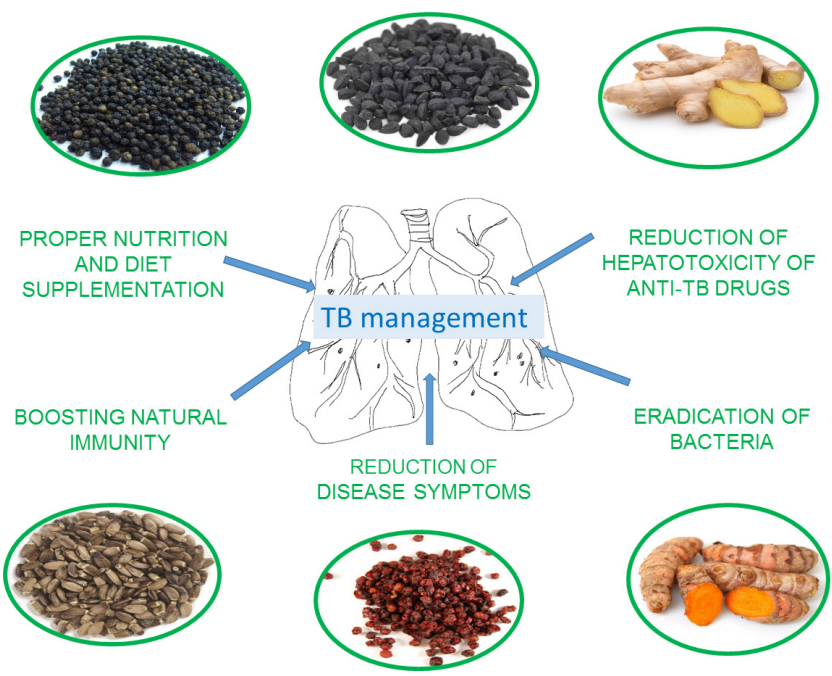

(C) 2020 International Association of Dietetic Nutrition and Safety. Publishing services by Atlantis Press International B.V. This is an open access article distributed under the CC BY-NC 4.0 license (http://creativecommons.org/licenses/by-nc/4.0/).

\section{INTRODUCTION}

While Tuberculosis (TB) is an ancient disease, it still remains one of top 10 causes of death globally and also a leading cause of death from an infectious agent, exceeding even Human Immunodeficiency Virus (HIV). Worldwide, an estimated 1.7 billion people are infected with Mycobacterium tuberculosis (Mtb). In 2018, an estimated 10.0 million people became ill with TB and almost 1.5 million of TB patients suffered death. Tuberculosis occurs in every part of the world but eight

*Corresponding author. Email: esieniawska@pharmacognosy.org

Peer review under responsibility of the International Association of Dietetic Nutrition and Safety countries with the highest TB burden (India, China, Indonesia, the Philippines, Pakistan, Nigeria, Bangladesh and South Africa) account for two thirds of the total new TB cases [1]. With early diagnosis and appropriate treatment most of the patients infected with TB can be successfully cured. However, $3.4 \%$ of new TB cases and $18 \%$ of previously treated cases had Rifampicin-resistant TB (RR-TB) or Multidrug-resistant TB (MDR-TB) which can be treated with significantly lower success rate. According to the latest $\mathrm{WHO}$ report the treatment success rate for MDR-TB is $56 \%$ globally. In recent years an increase of Extensively Drug-resistant TB (XDR-TB), defined as MDR-TB with additional resistance to at least one of the fluoroquinolones and one of the injectable agents used in MDR-TB treatment 
regimens, was observed. In the age of global population movements the emergence of MDR-TB and XDR-TB makes the treatment of TB an ongoing challenge [1]. An increasing number of economic refugees crossing the borders changed the epidemiological condition in many countries and increased the possibility of spreading infectious diseases. At the same time, the only licensed vaccine [Bacillus Calmette-Guérin (BCG)] for the prevention of TB, which was introduced almost 100 years ago, can prevent the development of severe TB forms in children but is not effective in adults [2]. The current recommendations for TB treatment require combination of different drugs and regimens lasting from 6 months (drug-susceptible TB) to 9-20 months (MDR-TB). However, in case of XDR-TB or when outcomes are not satisfactory, the duration of the treatment can be much longer [1]. The long lasting therapy, complexity of drug regimens, adverse effects exerted by many medications taken concurrently and drug-drug interactions during the treatment of coexisting diseases are the reasons of TB treatment failure [3]. The global clinical development pipeline for new anti-TB drugs and regimens summarized by WHO in August 2019 underline the necessity of increasing the efforts undertaken not only by pharmaceutical companies but also by not-for-profit organizations, academic institutions, small businesses or government agencies to improve TB treatment [1].

\section{TUBERCULOSIS - OLD DISEASE, TRADITIONAL TREATMENT}

Tuberculosis was proven to be an ancient disease with a wide geographic distribution. Samples with erosive lesions characteristic for tuberculosis-like infection were traced back to the Pleistocene [4]. The Egyptian mummies, dated back to 2400 BC, revealed skeletal deformities typical of tuberculosis. However, the first written evidence of TB were found in India and in China, and are dated as 3300 and 2300 years old, respectively [5]. The traditional medicine practiced by many tribes native to different continents is based on indigenous knowledge and provides valuable information on various natural products used in the treatment of this disease. The First Nations, who are predominant indigenous peoples in Canada south of the Arctic Circle, had developed natural remedies to manage $\mathrm{TB}$, however, the treatment was usually accompanied by various rituals based upon age-old traditions [6]. Recent ethnopharmacological surveys show that medical practises related to TB treatment and cultivated by natural healers are still alive and handed down from generation to generation in South Africa [7-10], Uganda [11], Ghana [12], Malaysia [13] and India [14]. The indigenous plant resources provide medications to alleviate cough and related respiratory disorders associated with TB. In the era of extensive high-throughput screening programs targeting potential anti-Mtb activity, researchers explore variety of plant species native to different parts of the world. The scientific efforts evaluating the rich flora of Mexico [15,16], South Africa [17], Ghana [12], Malaysia [13] or Colombia [18] aim to find new antibiotics among many diverse classes of plant secondary metabolites. Nevertheless, the plant extracts used by Natives are complex mixtures of large number of active compounds exerting synergistic effects and these beneficial effects are often lost after multi-step fractionation or isolation. What is more, the evaluation of antimycobacterial activity is mostly performed in vitro, ignoring many potential targets and natural mechanisms, like immune system present in a human organism. The traditional medicine, which is often based on a holistic approach, could provide a new and interesting perspective on TB treatment. This approach include not only the eradication of bacteria, but also boosting natural immunity, managing disease symptoms, as well as proper nutrition and diet supplementation [19]. Those goals can be achieved using plant-based food products.

This review describes natural products, with a focus on plant-based food products, useful in antimycobacterial therapy. It summarizes the antituberculous potential of ethnopharmacologically selected medicinal plants, herbs, spices and fruits. Moreover, the use of plant-based food products as supportive treatment of TB treatment is discussed. Proper diet supplementation in tuberculosis treatment is also considered.

\section{PLANT-BASED FOOD PRODUCTS TRADITIONALLY USED IN TB TREATMENT}

Since traditional healers utilize local resources to provide people with natural medicines, plant species used for the treatment of pulmonary tuberculosis vary significantly depending on the country. Survey performed by Lawal et al. [9] listed a total of 30 plant species belonging to 21 families as being used traditionally for the treatment of TB in Eastern Cape Province, South Africa. Nguta et al. [12] documented 15 plant species distributed between 13 genera and 13 families as still utilized for anti-TB treatments by local Ghanaian communities, whereas Madikizela et al. [7] identified 24 plant species belonging to 19 families that are used for treating TB in the eastern region of O.R. Tambo district in South Africa. Recently, Semenya et al. [10] surveyed traditional healers in the three districts of Limpopo Province, South Africa for the management of TB and reported 184 plant species distributed in 149 genera and 77 botanical families. A large number of these species were mentioned for the first time as medicines for TB and its opportunistic infections. Also, quite recently Gupta et al. [14] interviewed tribal traditional healers in Anuppur, Mandla, Umariya and Dindori districts of M.P., India and found 35 plant species distributed in 22 families with indications against TB.

The most frequently listed and validated plant species recommended in TB treatment and the management of associated diseases belong to Amaryllidaceae, Apiaceae, Asparagaceae, Asteraceae, Leguminosae, Rutaceae and Solanaceae botanical families $[13,17,20]$. Leaves, roots, bulbs, barks and fruits were used as plant remedies eaten directly or prepared as decoctions or infusions and sometimes burned and fumes inhaled [7,12,21]. Edible plants recommended in TB related coughs, chest ailments, chest pains and fever were: Abelmoschus esculentus; Acacia catechu; Agave sp.; Allium cepa; Allium sativum; Allium odorum; Aloe vera; Alpinia galangal; Amaranthus tricolor; Anacardium occidentale; Ananas comosus; Annona squamosal; Averrhoa bilimbi; Azadirachta indicia; Capparis brassii; Capparis tomentosa; Capsicum annum; Carica papaya; Cassia fistula; Centella asiatica; Cinnamomum camphora; Cinnamomum zeylanicum; Citrus microcarpa; Eucalyptus spp.; Ficus sur; Foeniculum vulgare; Fragaria vesca; Glycyrrhiza glabra; Humulus lupulus; Hypericum spp.; Juglans regia; Justicia flava; Kaempferia galangal; Lavandula angustifolia; Lupinus hirsutus; Mangifera indica; Mentha longifolia; Momordica charantia; Momordica foetida; Morus alba; Ocinum sanctum, Olea capensis; Opuntia spp.; Panax ginseng; Persea Americana; Phaseolus vulgaris; Phytolacca americana; Piper cubeba; Piper nigrum; Protasparagus africanus; Prunus Africana; Punica granatum; Rubus pinnatus; Rumex crispus; Salvia. spp.; Sambucus canadensis; Schizandra chinensis; Solanum torvum; Syzygium aromaticum; Tamarindus indica; Thymus vulgaris; Tulbaghia alliacea; Urtica dioica; Syzygium cordatum; Zingiber officinale [13,15,17,22,23]. 
The literature data clearly state that a large number of plant species traditionally used for TB management do not demonstrate significant antimycobacterial activity in vitro $[8,13,15,22,24]$. Even though they are still helpful to treat symptoms of the disease rather than to cure the disease itself [8]. The relieving of TB-related symptoms such as cough, chest pains and fever can be achieved by the administration of plant extracts exerting expectorant, bronchodilatory, anti-inflammatory, antipyretic or antitussive effects. Administration of Tussilago farfara, Cetraria islandica or Pulmonaria officinals was recommended for this purposes over a 100 years ago [25]. Natural products serve as adjuvants for classical antimycobacterial therapy, reducing severe side effects caused by synthetic drugs, enhancing activity of antibiotics and reinforcing the immune system to fight Mtb. The combination therapy of Chinese herbal medicines (single herbs, practitioner-prescribed herbal formulations or Chinese proprietary medicines) and anti-TB chemotherapy for MDR-TB evaluated in a number of randomized clinical trials appeared to be more effective than anti-TB chemotherapy alone in improving sputum bacteria conversion, lung lesions resorption, cavity closure, and reducing liver and kidney damage [26].

\section{PLANT-BASED FOOD PRODUCTS AS SOURCES OF COMPOUNDS TESTED AGAINST Mtb}

A vast variety of plant species are still being screened in order to find molecules inhibiting Mtb growth. The recent advances in the investigation of plant extracts active in vitro against sensitive and MDR-Mtb strains, inhibiting intracellular bacilli in vitro and ex vivo, and killing replicating and dormant bacteria were reviewed by Gupta et al. [27]. What is more, plant endophytes were also discovered as emerging source of active antimycobacterial agents [28,29]. However, because molecules active in nano- or micromolar concentrations are found rarely, the plant secondary metabolites were evaluated for their ability to enhance activity of antimycobacterial antibiotics. The synergistic action of plant extracts or isolated compounds against Mtb was already mentioned by Polak and Kapka-Skrzypczak [30], Gupta et al. [27] or Komape et al. [31]. Interestingly, the synergy was more frequently found when natural compounds were combined with rifampicin rather than with isoniazid or ethambutol $[32,33]$. These combinations showed variable activity against sensitive and drug resistant Mtb clinical strains [33-35] underlining the need to screen a wide panel of Mtb strains. The synergistic in vitro results, however, need to be validated using animal models and clinical trials, because in vivo synergy can result from increased antibiotic bioavailability, e.g. administration of piperine along with rifampicin [36], increased tolerability and functionality of the liver, e.g. piperine combined with rifampicin, isoniazid, pyrazinamide and ethambutol [37] or immunomodulated host response, as was shown in case of co-administration of rifampicin and piperine [38], rather than from the direct interaction with the bacilli.

\section{PLANT-BASED FOOD PRODUCTS USED FOR REDUCTION OF SIDE EFFECTS OF CLASSICAL ANTIMYCOBACTERIAL THERAPY}

Administration of antibiotics in TB treatment is related to serious adverse effects such as gastrointestinal disorders, ototoxicity, nephrotoxicity, skin rashes, fever, peripheral neuritis and hepatotoxicity [39].
The last being a result of drug-induced liver damage caused mainly by the first line anti-TB drugs; Rifampicin (RIF), Isoniazid (INH) and Pyrazinamide (PZA). The anti-TB drug-related hepatotoxicity affects $5-28 \%$ of treated patients and negatively affects clinical outcome, leading to therapeutic doses reduction and treatment failure $[40,41]$. It is also one of the major reasons for the discontinuation of therapy, which in effect contributes to the development of resistant Mtb forms [42-45]. Peroxidative damage to the liver induced by INH is related to reduced levels of glutathione $S$-transferase, catalase and superoxide dismutase and manifests as increased levels of the liver enzymes [46]. What is more, anti-TB drugs induce cytochrome P450 enzymes affecting the effectiveness of concurrent diseases management [47].

Co-administration of certain types of plant-based food products with anti-TB drugs was proven to be beneficial in protection of the liver, both in vitro and in vivo. The main indicators suggesting the improved condition of liver cells were decreased levels of enzymes: Alanine Transaminase (ALT), Alkaline Phosphatase (ALP) and Aspartate Transaminase (AST) observed after coadministration of plant extracts with anti-TB drugs in animal models. Such effect was observed for Garlic (Alium sativum) homogenate in rats [48], standardized aqueous onion (Alium cepa) extract in rats [49], standardized alcoholic extract from Terminalia chebula fruit containing $0.250 \%$ chebuloside in rats [50], sylimarin isolated from milk thistle (Sylibum marianum) in rats [51] and in rabbits [52], as well as for nanoparticle-formulated curcumin which significantly reduced liver lesions induced by INH as confirmed by lowering liver enzyme levels in mice [53]. Decreased levels of liver enzymes suggested the reduction of oxidative stress in liver cells [48]. Those results are consistent with earlier findings that garlic constituents, diallyl disulfide and diallyl trisulfide, up-regulate the expression of glutathione $S$-transferase, the enzyme involved in maintaining of oxidative balance and detoxification of xenobiotics, as was shown in clone- 9 cells derived from normal rat livers [54]. What is more, garlic polysulfides were recently found to have antimycobacterial activity as well as hepatoprotective effect against acetaminophen-induced toxicity in C3A liver cells [55]. The beneficial antioxidant action of plant secondary metabolites in protection of TB patient's liver was proven for sylimarin from milk thistle. In a double-blind randomized placebo-controlled trial, sylimarin was found to prevent liver damage in patients undergoing anti-TB treatment via restoration of the superoxide dismutase pool [42].

To conclude, administration of plant-based food products as adjunct therapy in TB treatment is beneficial in preventing and diminishing hepatotoxicity caused by anti-TB drugs, mainly via restoration of antioxidant enzymes, resulting in the decrease of liver enzymes levels.

\section{PLANT-BASED FOOD PRODUCTS AS IMMUNOTHERAPEUTIC AGENTS AGAINST TB}

Microbial infection and inflammation are two closely related processes ongoing during tuberculosis. The innate immune cells in the lungs, primarily macrophages, dendritic cells, monocytes, and neutrophils are critical for the early anti-mycobacterial responses, progression of the infection and long-term control of Mtb by continually developing adaptive immune responses and by regulating inflammation [56]. However, Mtb has evolved a number 
of strategies to abolish immune responses. Inhibited production of Interleukin 12 (IL-12) was observed in susceptible hosts with active pulmonary TB resulting in suppression of $\mathrm{T}$ helper type 1 cells (Th1) responses, manifested as lowered levels of Interferon gamma (IFN- $\gamma$ ) and Tumor Necrosis Factor (TNF- $\alpha$ ) [57-59]. What is more, it was shown that Mtb stimulates IL-10 production, thus facilitating Th2 responses that counter-regulate host-protective Th1 responses via IL-4 [58,59]. The bacteria-host interactions are further complicated by the side-activity of anti-TB drugs, which were proven to eliminate antigen-responding $\mathrm{T}$ cells during therapy leaving hosts hyper-susceptible to disease reactivation and reinfection [60-62]. Introduction of anti-inflammatory drugs to the conventional antibiotic treatment regimens allows to control the inflammation and improves the therapy effectiveness [63]. However, taking into account the side effects associated with prolonged administration of steroids, an alternative approach to redirection of the host immune response toward selective induction of Th1 cells and concomitant inhibition of Th2 cells is needed [59].

A number of research evaluating the usefulness of plant-based food products as boosters of host immune system against Mtb have emerged recently and show that those substances could restore the balance between the inflammatory and anti-inflammatory processes disrupted by the bacilli. Many of the studied plant extracts and isolated compounds provoked lymphocyte proliferation and consequently increased expression and release of related cytokines. This activity was observed for Miana leaves (Coleus scutellarioides) alcoholic extract, which stimulated T-lymphocyte proliferation and in result increased the number of Th cells and the levels of IFN- $\gamma$ and TNF- $\alpha$ in rats. The decreased number of Mtb colonies after miana extract treatment was not the effect of direct inhibition of bacteria proliferation but resulted from positively modulated host immunity [64]. Similar immunomodulatory activity inducing a strong protective Th1 response and supporting the direct killing of both susceptible and drug-resistant strains in vivo was reported for garlic extract in murine models of TB infection [65]. Also sylimarin, a mixture of flavonolignans (silibinin, isosilibinin, silicristin, silidianin) from milk thistle (Sylibym marianum) seeds, induced a significant expression of Th- 1 cytokines: IFN- $\gamma$, IL-12 and TNF- $\alpha$, when administered alone or in combination with chemotherapy in mice infected with drug-sensitive or MDR mycobacteria [66]. Another example of indirect bacteria clearance and adjuvant activity when combined with rifampicin is piperine, an alkaloid from black pepper (P. nigrum). Piperine acted synergistically through stimulation of mouse splenocytes leading to lymphocyte ( $\mathrm{T}$ and $\mathrm{B}$ cells) proliferation, Th-1 cytokine production and macrophage activation ex vivo. It activated the differentiation of T cells into Th-1 sub-population (Th/Tc subsets), increased the secretion of IFN- $\gamma$ and IL- 2 as well as the expression of IFN- $\gamma$ and IL-2 mRNA transcripts in the infected lung tissues in mouse infection model of Mtb [38]. The corresponding immunomodulatory effects described in animal models were also confirmed in humans ex vivo and in vivo. Aqueous extract of chanca piedra (Phyllanthus niruri) increased mononuclear cells proliferation and macrophage activity, including phagocytic activity in TB patients ex vivo [67]. The same extract given concomitantly with the standardized anti-TB regimens regulated immune responses in patients with active pulmonary TB and caused a significant elevation of IFN- $\gamma$ and TNF- $\alpha$ plasma levels and simultaneous decrease of IL-10 release. What is more, chanca piedra extract markedly elevated the number of peripheral Th cells and $\mathrm{Th} / \mathrm{Tc}$ (T-killer cells) ratio and, as a result, it facilitated the inflammatory response required to eradicate the microbes $[68,69]$.
Detailed examination of the influence of allicin from garlic on the host immunity during Mtb infection found that allicin treatment enhanced the activation of the SAPK/JNK pathway in macrophages and resulted in the inhibition of p38-MAPK phosphorylation and decreased TNF- $\alpha$ production by infected macrophages [65].

Other important observations after the administration of plant extracts, concomitant with restored Th1/Th2 balance, were increased antioxidant capacity within macrophages and induced surface expression of molecules important in initiation of immune responses. The first mechanism was described for extracts from selected Rubiaceae species, which inhibited the replication of mycobacteria by stimulating the macrophages to release pro-inflammatory cytokines and to scavenge free radicals [67]. Additionally, the inhibition of 15-lipoxygenase enzyme pathway was observed leading to the induction of programmed cell death and prevention of intracellular growth of Mtb [70]. The second mechanism was revealed for an acidic arabinogalactan polysaccharide derived from Tinospora cordifolia used to stimulate Mtb infected RAW264.7 macrophages in vitro. The stimulation significantly induced the surface expression of MHC-II and CD-86 molecules important in initiating immune responses. However, it also caused an increased secretion of proinflammatory cytokines (TNF- $\alpha$, IL- $\beta$, IL-6, IL-12, IFN- $\gamma$ ) and nitric oxide [71]. As a result of the polysaccharide immunomodulatory activity, the intracellular survival of sensitive and MDR Mtb strains was reduced [71]. Further in vivo investigation confirmed similar effects in the lungs of Mtb infected mice treated with arabinogalactan polysaccharide. The acidic arabinogalactan polysaccharide upregulated the expression of TNF- $\alpha$, INF- $\gamma$ and Nitric Oxide Synthase 2 (NOS2) in the mice lung tissue, elevated the levels of Th1 cytokines (IFN- $\gamma$, IL-12) and decreased the levels of Th2 cytokine (IL-4) in the serum. Restoration of Th1/ Th2 balance resulted in better animal protection against Mtb in comparison to the INH treatment [71]. Similar positive effects on phagocytic activity of macrophages infected with Mtb and on the secretion of cytokines ex vivo was observed for polysaccharides and astragalosides isolated from Astragalus membranaceus. Both fractions of active compounds enhanced secretion of IL- $1 \beta$, IL- 6 and TNF- $\alpha$ in activated macrophages [67,72].

More complex immunomodulatory action with a beneficial effect on restoration of memory immune responses and protection from reinfection was shown for curcumin, the main active constituent of Curcuma longa. Curcumin was proven to increase the ability of human monocytic cells (THP-1 cell line) infected with Mtb to control infection via inhibition of NFKB activation and induction of apoptosis and autophagy through caspase-3 dependent pathway [73]. Because NF- $\kappa \mathrm{B}$ induced by Mtb provoke the expression of enzymes involved in the development of inflammatory process, such as the Inducible NOS (iNOS) and the inducible Cyclooxygenase (COX-2), generating nitric oxide and prostanoids, respectively, the inhibition of NF- $\kappa \mathrm{B}$ activation helps to control host inflammatory and immune responses and prevents chronic inflammation [74]. Thus, curcumin can be an alternative to steroids administered in the TB management. Moreover, curcumin nanoparticles reversed INH-induced immune dysfunction of T cells in vitro and restored the INH-induced suppression in antigen-specific cytokine responses in mice TB model [53]. Curcumin also prevented apoptosis induced by antibiotics in antigen-responding activated $\mathrm{T}$ cells by inhibiting activation of the caspase-3 pathway [53]. Co-treatment with curcumin nanoparticles increased the total number of splenocytes and enhanced the activation of both Th and Tc cells during primary infection. What is more, 
introduction of curcumin nanoparticles to the treatment regimen contributed to the restoration of memory immune responses and consequent protection of animals from reinfection. The ability of curcumin nanoparticles to protect against post-treatment infection was correlated with enhanced generation of central memory T cells [53].

As was shown above, the antimycobacterial action of plant-based food products is often the result of immunomodulatory properties and boosting the immune system to fight Mtb. Even plants inactive or weakly active in vitro against bacilli can provoke bacteria clearance but mainly by acting synergistically when combined with anti-TB drugs. The introduction of plant-derived food products as immunomodulatory agents administered as adjuvants in TB chemotherapy could be a solution to shorten the duration of treatment regimen, increase the successful bacteria clearance, minimize generation of drug resistant bacteria and lower the incidence of reinfection and disease reactivation.

\section{THE ROLE OF PLANT-DERIVED FOOD PRODUCTS IN TUBERCULOSIS TREATMENT}

The tuberculosis prevalence is undoubtedly correlated with malnutrition among patients in developing countries [1]. Malnutrition can impair host immune responses against Mtb infection, as was nicely summarized by Gupta et al. [75].

Protein deficiency contributes to enhanced bacterial growth and dissemination due to thymic atrophy and impaired generation and maturation of T-lymphocytes, but also due to impaired protective interaction between macrophages and T-lymphocytes, higher production of transforming growth factor- $\beta$ being a mediator of immunosuppression and immunopathogenesis in tuberculosis, decreased production of Th1 cytokines and loss of tuberculosis resistance following BCG vaccination. All these effects were observed in animal models, because, as highlighted by Cegielski and McMurray [76], it is hardly possible to determine the nutritional status in TB patients prior to the onset of the disease. Also more recent work by Chandrasekaran et al. [77] underlined the role of macro- and micro-nutrients in immunomodulation in tuberculosis. Among micronutrients, the influence of vitamins A, D, E, C, selenium, zinc, iron and copper on the host defense functions against $\mathrm{Mtb}$ was described and verified in a number of clinical trials [75,77]. Micronutrients supplementation resulted in significantly better lymphocyte proliferation and immune responses when administered as adjuvant to MDR-TB therapy. A higher rate of TB-negative sputum patients and lower mean lesion area in the lungs was recorded after the treatment [75]. Interestingly, new cases of Mtb infection were associated with inadequate intake of not only certain vitamins and minerals but also fruits and vegetables [78]. Moreover, the progressive shift from traditional, home cooked meals to processed food contributes to insufficient supply of nutrients essential to maintain proper functions of the immune system. Poor nutrient value and low variety of ingredients in ready-to-eat foods justify the need of the re-introduction to the patients diet the plants rich in vitamin $\mathrm{A}$ (carrots, spinach, waterleaf, and tomato), vitamin D3 (tomato, potato, pumpkin, and alfalfa red pepper), vitamin E (grains and nut oils) or vitamin $\mathrm{C}$ (citrus fruits, strawberries, cantaloupe, tomatoes, cabbage, and green leafy vegetables) [79]. Also plants with high protein content such as soy or lentil were shown to be beneficial in tuberculosis therapy [80,81]. Thus, the TB treatment schemes including anti-TB drugs and proper diet composition and supplementation are essential to successful bacteria clearance. Also plants showing general immunomodulatory properties like Angelica sinensis, Andrographis paniculata, Ligusticum chuanxiong, Nigella sativa, Panax ginseng [82] and already validated as immune boosters in TB treatment like, A. sativum, A. membranaceus, C. scutellarioides, C. longa, P. nigrum, P. niruri, S. marianum $[38,53,64-69,72,73]$ can be beneficial and improve the anti-TB chemotherapy.

\section{EXAMPLES OF PLANT-DERIVED FOOD PRODUCTS WITH PROVEN ANTIMYCOBACTERIAL ACTIVITY}

Selected plant species investigated for their usefulness in TB management are described here to underline the progress in the holistic approach to the disease treatment. The main directions of activities exerted by plant-based food products are presented in Figure 1 and summarized in Table 1. Figure 2 shows main secondary metabolites related to described beneficial effects.

\subsection{Zingiber officinale Roscoe}

Zingiber (Zingiberaceace) originates from China, where it has a long history of cultivation as a spice and as a traditional medicinal plant. Ginger grows naturally in subtropical and tropical Asia, Africa, Far East Asia, China, and India. In these regions, it is traditionally used to treat headaches, nausea, colds, flu, cough and asthma, arthritis, rheumatism, muscular discomfort and inflammation [83,84]. Modern scientific studies have proven ginger's ethnobotanical usage as a herbal remedy to cure symptoms associated with TB by local communities in Uganda and Ghana $[20,85,86]$. Such activities of ginger as antibacterial, antioxidant, anti-inflammatory, neuroprotective or anticancer can be attributed to bioactive constituents as gingerols, shogaols, gingerdiones, gingerdiols and paradols [87]. Importantly, due to its long history of use, ginger is considered as safe by FDA.

\subsubsection{In vitro antimycobacterial activity}

The antimicrobial activity of ginger was recently reviewed [88] showing very weak antibacterial properties of extracts and better of essential oil obtained from ginger rhizomes. The in vitro examination of different fractions of essential oil obtained from ginger rhizomes against Mtb and nontuberculous mycobacteria showed minimal inhibitory concentration (MIC) values ranging from 31.25 to $>250 \mu \mathrm{g} / \mathrm{mL}$ and from 15.6 to $>250 \mu \mathrm{g} / \mathrm{mL}$, respectively. The best activity was observed for fraction containing $\gamma$-eudesmol as the main compound [89]. The ethanolic extract of ginger showed poor activity against Mtb reference strains in vitro with the MIC of 2.5 and $10 \mathrm{mg} / \mathrm{mL}$ for strains H37Ra and H37Rv, respectively [86]. Whereas, an isolated 10-gingerol was shown to be a better inhibitor of Mycobacterium avium and Mtb with a MIC values of 25 and $50-100 \mu \mathrm{g} / \mathrm{mL}$, respectively [90]. Other phenyldecanoid derivatives present in the hexane extracts of $Z$. officinale, namely 6-shogaol and 6-gingerol, exhibited good activity against Mtb H37Rv, with MIC values of 64 and $33 \mu \mathrm{g} / \mathrm{mL}$, respectively [91]. 


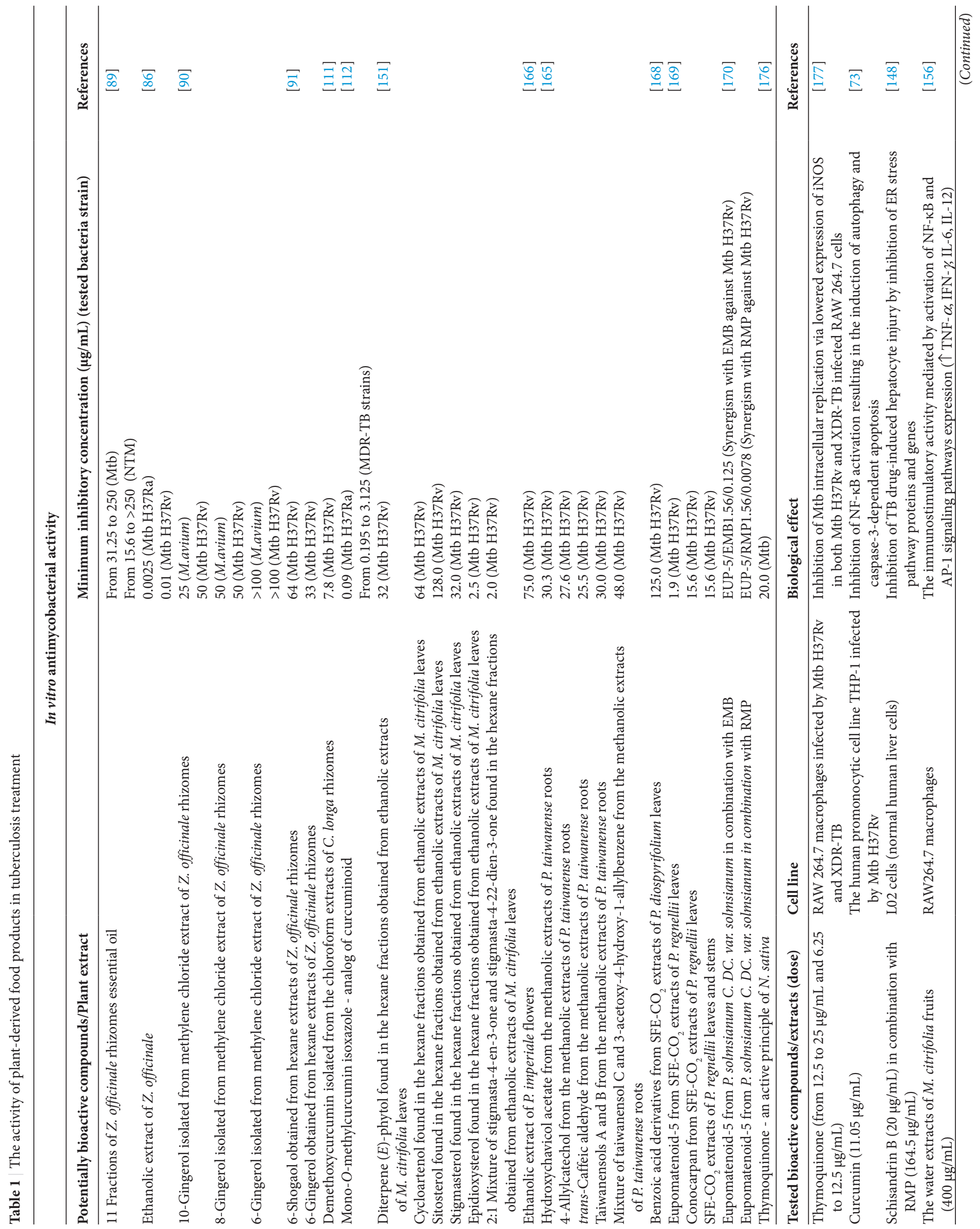




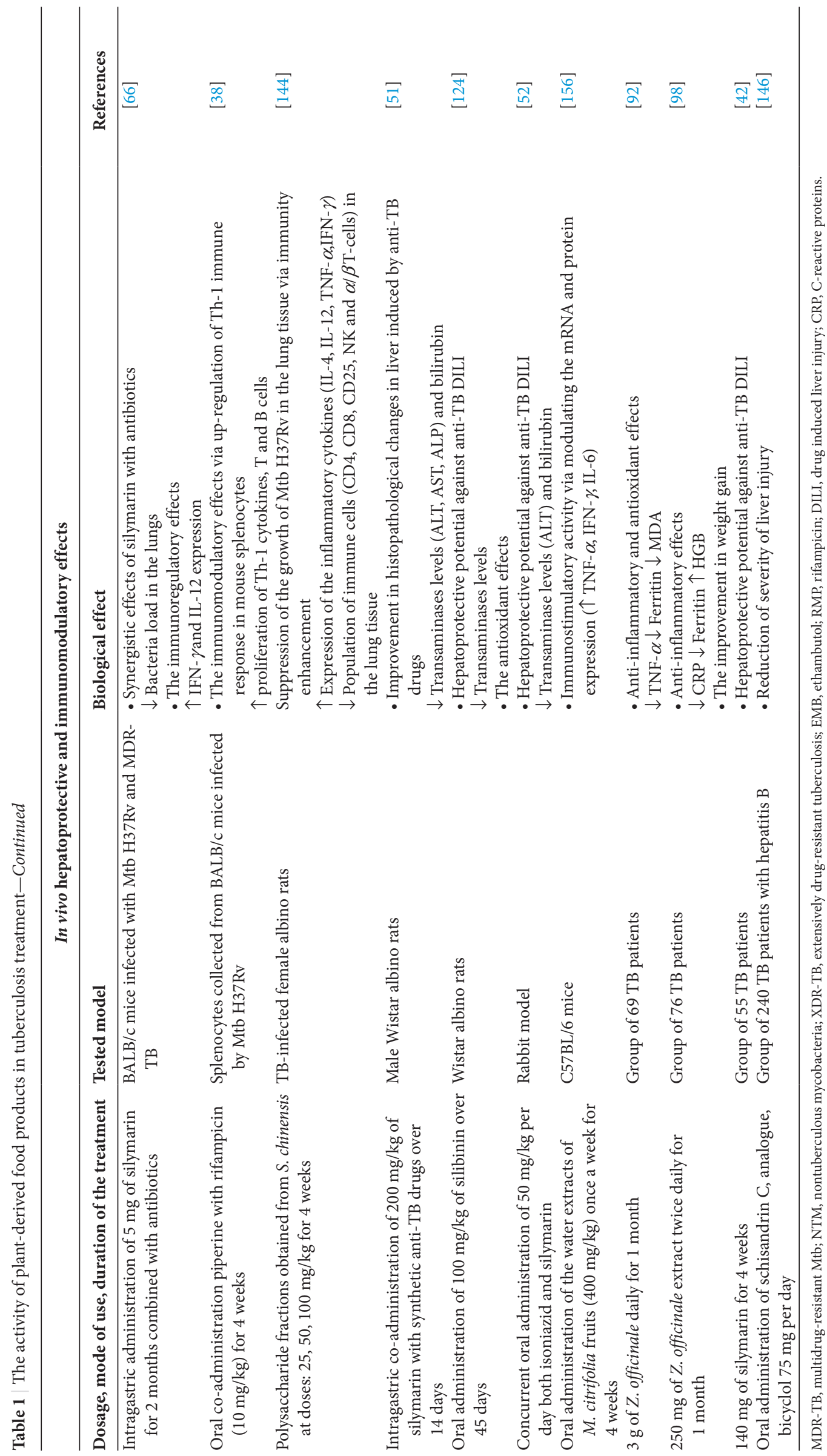




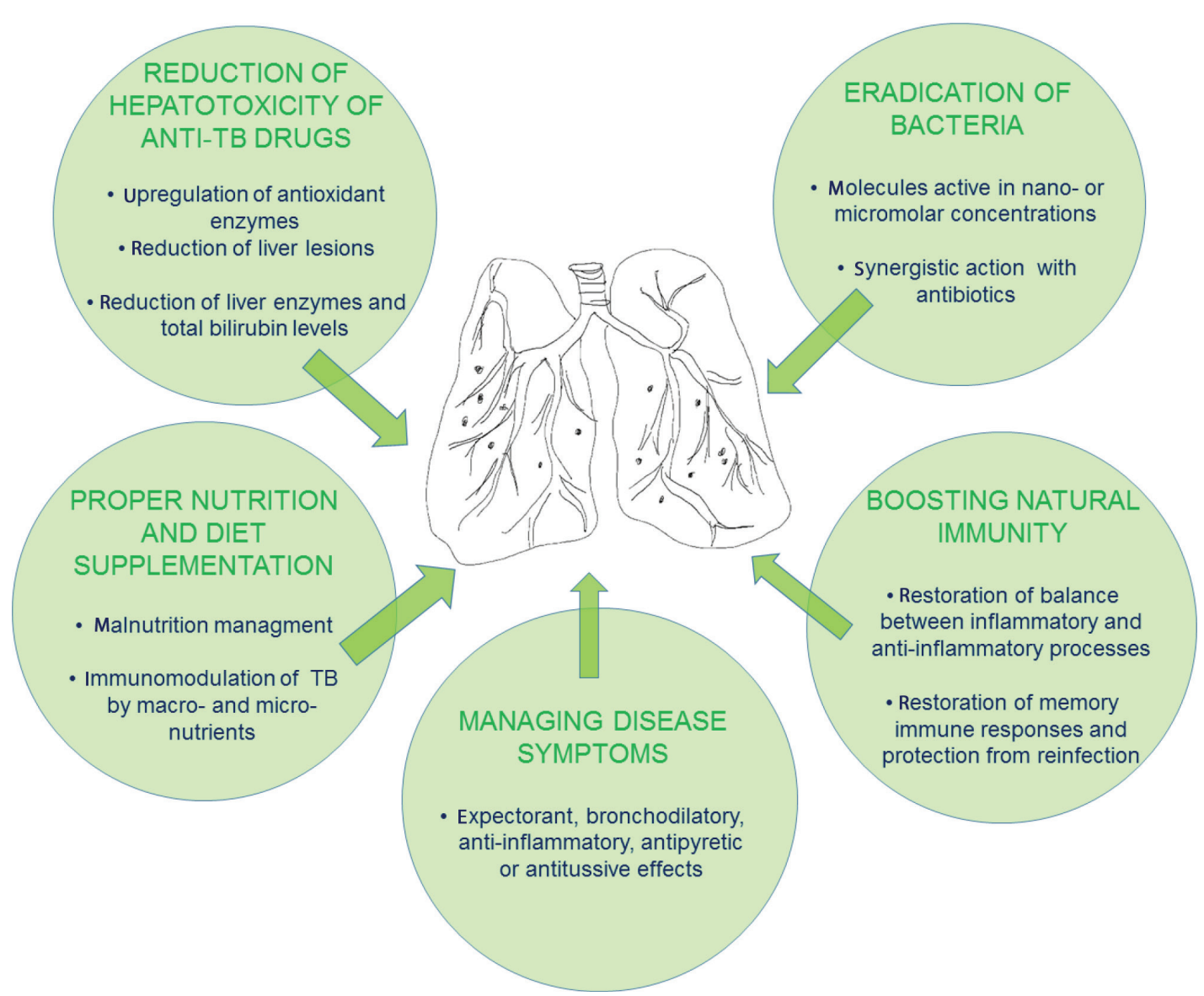

Figure 1 The main directions of activities exerted by plant-derived food products in TB management.<smiles>CCCCCCCCCC(O)CC(=O)CCc1ccc(O)c(O[N+](=O)[O-])c1</smiles>

1<smiles></smiles><smiles>COc1cc(/C=C/C(=O)CC(=O)/C=C/c2ccc(O)c(OC)c2)ccc1O</smiles><smiles>COc1cc(/C=C/C(=O)CC(=O)/C=C/c2ccc(O)cc2)ccc1O</smiles><smiles>COc1cc2c(OC)c(OC)c1OCCO2</smiles>

6<smiles>O=C(/C=C/C=C/c1ccc2c(c1)OCO2)N1CCCCC1</smiles>

3<smiles>O=C(/C=C/c1ccc(O)cc1)CC(=O)/C=C/c1ccc(O)cc1</smiles><smiles>CC1=CC(=O)C(C(C)C)=CC1=O</smiles>

Figure 2 The examples of main secondary metabolites of plant related to the beneficial effects in the TB management: 1 - 10-gingerol; 2 - curcumin; 3 demethoxycurcumin; 4 - bisdemethoxycurcumin; 5 - silybinin; 6 - schisandrin C; 7 - piperine; 8 - thymoquinone. 


\subsubsection{In vivo studies}

\subsubsection{Antiinflammatory and antioxidant activity in TB}

Ginger was shown to exert immunomodulatory activities. A randomized and placebo-controlled study in pulmonary TB patients (69 individuals) revealed that co-administration of ginger with anti-TB treatment for 1 month was beneficial, because of observed anti-inflammatory and antioxidant effects. Introduction of $3 \mathrm{~g}$ of ginger extract into daily diet for 1 month resulted in lowered levels of TNF- $\alpha$, ferritin and Malondialdehyde (MDA) in blood samples in comparison to control group [92]. These results were consistent with previous findings that gingerol, shogaol, and other structurally-related ginger constituents inhibit biosynthesis of prostaglandin and leukotriene through suppression of 5-lipoxygenase or prostaglandin synthase, decreasing the production of pro-inflammatory cytokines (IL- 1, TNF- $\alpha$, and IL-8) and downregulating the expression of iNOS and COX-2 genes [93-95], underlining its possible usefulness as anti-inflammatory agent in tuberculosis.

\subsubsection{Nutraceutical value in TB}

Ginger is also known for its nutraceutical value. The administration of ginger metabolites in rat model resulted in increased adrenal catecholamine secretion and improvement of the appetite [96,97], indicating that $Z$. officinale may influence the host energy consumption and may be a valuable ingredient of functional food used during anti-TB treatment. Other interesting study, conducted by Kumar et al. [98], involving 76 newly diagnosed sputum positive pulmonary TB patients having significant anaemia and receiving anti-TB treatment supplemented with $250 \mathrm{mg}$ of ginger extract twice daily after meals for 1 month, showed a significant decrease in serum levels of C-reactive proteins and ferritin, high increase of haemoglobin level and improvement of standard biochemical parameters. Moreover, increased serum levels of iron were also noticed at the end of the investigation indicating that acute phase response interacts with the iron metabolism. The improvement in weight gain was significantly higher in ginger supplemented group compared with the anti-TB treatment alone suggesting a better restoration of nutritional status of patients and confirming that ginger is a promising adjuvant in TB therapy [98].

\subsection{Curcuma longa L.}

Another plant with interesting and versatile biological activity, belonging to ginger family, is C. longa L. (turmeric). Its rhizomes have a long history of use in the traditional Chinese medicine as a flavoring agent and ayurvedic remedy to treat various diseases, primarily associated with skin and gastrointestinal tract. The tumeric's effects on health stems from principal bioactive component - curcumin, also called "Indian Yellow Gold" due to its brilliant yellow color $[53,99]$. It has been determined that the chemical structure of curcumin possess strong structural homology to bioactive molecules derived from ginger (gingerol), alpinia (yakuchinone A) and red chilli (capsaicin) [100].

Over the last 50 years, preclinical and clinical studies have provided strong evidence of curcumin safety and effectiveness in the prevention and treatment of numerous human illnesses, ranging from cancer to autoimmune disorders, diabetes and neurological diseases via antioxidative, anti-inflammatory and antiapoptotic activity [101-104]. Wide range of reported biological effects of curcumin is due to its pleiotropic properties which involve modulating multiple molecular targets involved in pathogenesis of various diseases [100,105-107].

\subsubsection{In vitro antimycobacterial activity}

Commercially available curcumin is actually a mixture of curcuminoids: curcumin, demethoxycurcumin and bisdemethoxycurcumin [108]. Scientific data suggests that structural modifications of curcumin may lead to the development of analogs with improved bioavailability and pharmacokinetic profile. This may have an impact on antimycobacterial activity but also on anti-inflammatory and anticancer properties of curcumin derivatives compared to curcumin $[109,110]$. Particularly, monocarbonyl analogs have attracted a great interest for the development of novel curcumin-based constituents. Several of them have been screened for antitubercular effects. The study conducted by Baldwin et al. [99] revealed that they inhibit the growth of pathogenic of $M$. tuberculosis and related Mycobacterium marinum, as well as rifampicin-resistant Mtb strains [99]. Other authors evaluated chloroform extract of C. longa $(1000 \mu \mathrm{g} / \mathrm{mL})$ and its main component - demethoxycurcumin (200 $\mu \mathrm{g} / \mathrm{mL}$ ) against $M$. tuberculosis $\mathrm{H}_{37} \mathrm{Rv}$ and found that demethoxycurcumin was more potent, however, chemical modification of demethoxycurcumin yielded a derivative showing 25 -fold increase in antitubercular activity [111].

Curcuminoids were demonstrated to be active also against the non-virulent $M$. tuberculosis $\mathrm{H}_{37}$ Ra strain [112] and their subsequent chemical modification provided isoxazole analogs of curcuminoids with improved antimycobacterial properties. Among those derivatives the highest activity was found for mono-O-methylcurcumin isoxazole with MIC of $0.09 \mu \mathrm{g} / \mathrm{mL}$. An isoxazole ring and two unsaturated bonds on the heptyl chain which were present in modified moiety and allowed for greater antitubercular effect in comparison to curcumin $(100 \mu \mathrm{g} / \mathrm{mL})$ and reference drug kanamycin $(2.5 \mu \mathrm{g} / \mathrm{mL})$ and comparable to isoniazid $(0.06 \mu \mathrm{g} / \mathrm{mL})$. Interestingly, mono-O-methylcurcumin isoxazole was also active against various MDR clinical isolates of Mtb with MIC values between 0.195 and $3.125 \mu \mathrm{g} / \mathrm{mL}$. Furthermore, according to the authors, curcuminoids unique skeleton is different from the currently used antitubercular medications which may prevent the possibility of cross resistance of these analogs with other TB drugs [112].

\subsubsection{Ex vivo and in vivo studies}

\subsubsection{Immunomodulatory and hepatoprotective activity in TB}

According to the literature data there is a proven link between curcumin anti-inflammatory and immunoregulatory effects in hosts and its beneficial properties against tuberculosis. There are numerous research investigating the mechanisms by which curcumin can display its immune-adjunctive effects in immune system related illnesses [113-115]. For instance, Bai et al. [73] reported that curcumin was found to reveal its immunomodulatory properties in 
human macrophage TB infection model. Curcumin up-regulated apoptosis and autophagy in Mtb-infected macrophages probably through the activation of caspase- 3 .

However, the application of curcumin in therapy still remains a challenge. Its relatively low bioavailability and high doses required to exert health-promoting effects, significantly reduce clinical application. Therefore, to overcome those limitations a number of technologies have been developed to improve curcumin's pharmacokinetic properties and raise its therapeutic value [116]. New oral delivery systems for this compound have been recently designed, e.g., nanoparticles of curcumin ( $200 \mathrm{~nm}$ in size), formulated by Tousif et al. [53] were found to possess fivefold higher bioavailability in animals than regular curcumin. Importantly, the combined administration of curcumin nanoparticles along with antimycobacterial antibiotics used in TB therapy may reduce their hepatotoxicity and minimalize the risk of tuberculosis reactivation [53,115]. Furthermore, the curcumin nanoparticles have been reported to activate the host immune response and increase the efficacy of BCG vaccine commonly used to prevent disseminated and meningeal tuberculosis in young children [117].

\subsection{Silybum marianum (L.) Gaernt. (Sm)}

The milk thistle, a plant belonging to Asteraceae family, is now one of the most extensively studied liver protective natural drugs with long tradition of use dating back to the 4th century B.C. [43]. Its seeds are the source of silymarin, well-established standardized extract comprised of a mixture of flavonolignans, mainly silybinin, silydianin and silychristin [66]. Silymarin is recommended in alcohol and drug-induced liver injuries, in case of mushroom poisoning and in chronic hepatitis B treatment [118-120]. Most of silymarin's biologically relevant properties are attributed to its main component - silybinin [66]. Numerous animal studies and clinical trials revealed significant hepatoprotective activity of the extracts containing silymarin [121]. To date, its proved high safety profile without any major adverse effects, make it a promising adjuvant in anti-TB treatment of natural origin [122].

\subsubsection{In vivo studies}

\subsubsection{Hepatoprotective activity in TB}

There are evidences that silymarin may prevent liver cell damage, stabilize the membrane potential and restore the normal function of hepatic enzymes [42,45]. According to Tasduq et al. [123], silymarin may be responsible for reversion of the abnormal increase of enzymes including AST and ALT, caused by co-administration of rifampicin, isoniazid and pyrazinamide in rats. Other study, conducted by Eminzade et al. [51] confirmed silymarin's liver protective effects in animal hepatotoxicity model. The simultaneous intragastric administration of silymarin $(200 \mathrm{mg} / \mathrm{kg})$ together with different combinations of anti-TB drugs over 14 days caused a significant reduction of liver damage observed as a decline of enzyme activity (ALT, AST, ALP) compared to animal group that received TB-drugs alone. Improvement of histopathological changes induced by synthetic TB-drugs in silymarin animal group, correlated well with biochemical results [51]. Jahan et al. [52] demonstrated that combinational therapy of isoniazid and silymarin $(50 \mathrm{mg} / \mathrm{kg} /$ day $)$ resulted in a decrease of serum ALT level induced by INH in rabbit model. Similar results were reported by Raghu and Karthikeyan [124], where the intake of silymarin $(100 \mathrm{mg} / \mathrm{kg}$ ) contributed to the alleviation of toxic effects induced by zidovudine and isoniazid.

Silymarin hepatoprotective effects had been demonstrated in numerous animal and in vitro experiments. However, its clinical efficacy in anti-TB drug-induced liver injury still remains controversial. A double-blinded randomized controlled trial designed by Luangchosiri et al. [42], performed in human, showed a positive hepatoprotective effects of silymarin intake after 4-week treatment. The risk of the occurrence of anti-TB drug-induced liver injury in the silymarin treated group was approximately $28 \%$ lower than in the placebo one. In contrary, Marjani et al. [43] and Zhang et al. [125] observed no significant effect of silymarin on the risk on drug-induced hepatitis. However, because of a limited sample size and study period, further clinical trials are required. The long-term administration of TB-drugs leads to liver dysfunction and damage by increased production of oxygen free radicals. The molecular mechanism underlying the activity of the standardized extract of silymarin is not fully understood, but it has been linked to the antioxidant and radical scavenging properties [66].

\subsubsection{Anti-inflammatory and immunomodulatory activity in TB}

Silymarin was also reported to exert anti-inflammatory and immunomodulatory activity which may also play a crucial role during antituberculosis therapy [66,126]. Zhang et al. [127], investigated silymarin mechanisms of action in an animal model of alcoholinduced liver injury. It was found to exert anti-inflammatory effect via down-regulation of the expression of NF- $\kappa B$, intercellular adhesion molecule- 1 and IL- 6 genes in liver tissue. Silymarin administered in combination with primary anti-TB drugs has a potential therapeutic effect during mycobacterial infection. RodriguezFlores et al. [66] suggested that silymarin used as an adjuvant in the TB-chemotherapy increase the effectiveness of bacteria eradication and could considerably avert TB-drug associated hepatotoxicity, resulting in improved treatment outcome. What is more, silymarin was found to boost host immune response in TB by increasing the expression of protective Th- 1 cytokines like IFN- $\gamma$, IL-12 and TNF- $\alpha$ and directly decreased in vitro the viability of both the MDR and drug-sensitive Mtb H37Rv strains at doses higher than $50 \mu \mathrm{M}$. All of these effects are important in the immune system protection against tuberculosis, because in humans and mice organisms the activation of Th- 1 cytokines and macrophages lead to NO and oxygen free radicals production which was found to be crucial to eliminate Mtb [66].

\subsection{Schisandra chinensis}

Schisandra chinensis (Turcz.) Baill. - Chinese magnolia is a wellknown worldwide medicinal plant adaptogen, cultivated mainly in Asia and Eastern parts of Russia. The red edible berries of S. chinensis called Wuweizi in Chinese, meaning "five flavour fruit", which refers to its characteristic taste, has been commonly used in tea, wine and beverages [128-130]. Schisandra chinensis has been a fundamental astringent constituent of various prescriptions used for thousands of years in Traditional Chinese Medicine. The dry ripe fruit of $S$. chinensis is officially documented in the Chinese 
Pharmacopoeia as a tonic and sedative [131,132]. It is currently known to be an adaptogenic herb which provide beneficial effects in a wide range of health ailments, such as stress, chronic fatigue and nervous exhaustion. Recently, S. chinensis gained tremendous attention in western-based medicine due to its abundant bioactivities, including antioxidant, anti-inflammatory, antiviral and anticancer properties [133]. Phytochemical investigations of schisandra berries resulted in the identification of various compounds, among which lignans, namely schisandrins and gomisins, were found to be major constituents responsible for diverse pharmacological effects [134-136]. The hepatoprotective properties of those berries, being the best documented activity of S. chinensis, were found to be effective in managing liver damage induced by carbon tetrachloride, alcohol or acetaminophen [137-139]. Medical preparations based on extracts obtained from S. chinensis berries and the synthetic analogues of active component-schisandrin C, are currently marketed in Asian countries for the treatment of chronic viral hepatitis and drug induced liver injury [128,136,140].

\subsubsection{In vivo studies}

\subsubsection{Virostatic and immunomodulatory activity}

The probability of developing TB disease is much higher among people infected with HIV. Among all TB cases reported in 2018, 8.6\% were people living with HIV. Moreover, there were approximately 251,000 deaths due to the TB among HIV-positive people [1]. According to Habibi et al. [141] the treatment of HIV in TB infected patients is an appropriate tool to fight tuberculosis and vice versa. Both pathogens, HIV and Mtb, are considered to intensify the severity of symptoms of these two high-burden diseases in a synergistic manner, leading in the final stage to breakdown of the host immune system and premature death [141]. Schisandra chinensis may be considered a plant capable of braking this HIV-TB link. The dibenzocyclooctadiene lignans found in different species of Schisandra were reported to reveal inhibitory effects against HIV replication [142,143]. Whereas, study conducted by Huang et al. [144] showed polysaccharides to be responsible for inhibiting Mtb $\mathrm{H} 37 \mathrm{Rv}$ in the lung tissue of TB-infected rats. Results of investigations provide evidence that $S$. chinensis might be considered as a promising natural product which effectively eliminates both pathogens, probably via enhancement of both cellular and humoral immunity [145]. The immunomodulatory properties of bioactive constituents derived from S. chinensis fruit may play a key role in both antibacterial and liver protective activity.

\subsubsection{Hepatoprotective activity in TB}

Hepatoprotection of $S$. chinensis constituents against anti-TB drug-induced liver injury was studied in animal models and in clinical trials. One of the schisandrin C analogues, bicyclol, showed significant liver protective effects in anti-TB drug intoxicated rats. The administration of bicyclol (100 and $200 \mathrm{mg} / \mathrm{kg}$ ) tended to reverse elevated serum transaminases levels (ALT, AST, ALP) in treated group [146]. Numerous clinical studies have found S. chinensis effective in the treatment of drug induced liver injury caused by anti-TB drugs. Zhu et al. [140] summarized the clinical trials conducted in China, investigating different Chinese traditional formulations containing schizandra in patients receiving anti-TB therapy. The Wuwezi granule were shown to be more effective in preventing anti-TB drugs induced liver injury than glucurolactone, the basic liver protectant. Co-treatment with Wuwezi capsules for 4 weeks significantly normalized elevated levels of serum biochemical parameters (ALT, AST, bilirubin and $\gamma$-glutamyltransferase) and reduced the incidence of anti-TB drug-induced liver failure (47\%) in TB patients. Another study demonstrated that co-administration of schisandra-derived capsules with anti-TB drugs for 6-12 months may mitigate the severity of biochemical changes compared to control group receiving only antituberculosis treatment [140]. What is more, the administration of glucurolactone, in conjunction with bicyclol at dosage of $75 \mathrm{mg} /$ day p.o. significantly reduced the occurrence of liver injury caused by anti-TB therapy in comparison to control $(p<0.05)$. Furthermore, other clinical study revealed bicyclol to be more effective in preventing anti-TB induced liver injury than silybinin $[147,148]$.

The mechanism of hepatoprotective action of dibenzocyclooctadiene lignans derived from $S$. chinensis and their synthetic analogues in case of anti-TB induced liver injury may be associated with antioxidant and antiradical effects. It has been implicated that the inhibition of hepatic lipid peroxidation and consequently alleviation of hepatic injury may play a pivotal role in liver protective mechanisms of schisandra constituents. Schisandra chinensis co-administration with anti-TB drugs makes the treatment safer and may help to reach therapeutic drug levels, but also increases the recovery rate in tuberculosis patients [149].

\subsection{Morina citrifolia Linn.}

Morina citrifolia Linn. generally known as "noni" is one of the most important Polynesian medicinal herbs. Its edible leaves and fruits were used by traditional healers to treat skin lesions and wounds. Indigenous population of Australia used noni plant for the treatment of respiratory diseases [150].

\subsubsection{In vitro antimycobacterial activity}

Some scientific evidence supports its traditional recommendations and noni was considered as a plant with potential application in TB treatment. The study conducted by Saludes et al. [151] revealed that the crude ethanolic (50\%) extract and hexane fractions obtained from M. citrifolia leaves showed $89 \%$ and $95 \%$ inhibition against Mtb H37Rv strains at $100 \mu \mathrm{g} / \mathrm{mL}$. According to the study, the noni anti-TB properties can be attributed to the presence of lipids in the hexane fractions: diterpene (E)-phytol (MIC of $32 \mu \mathrm{g} / \mathrm{mL}$ ); triterpenes: cycloartenol (MIC of $64 \mu \mathrm{g} / \mathrm{mL}$ ); sitosterol (MIC of 128 $\mu \mathrm{g} / \mathrm{mL}$ ); stigmasterol (MIC of $32 \mu \mathrm{g} / \mathrm{mL}$ ) and epidioxysterol (MIC of $2.5 \mu \mathrm{g} / \mathrm{mL}$ ); $2: 1$ mixture of the ketosteroids: stigmasta-4-en-3one and stigmasta-4-22-dien-3-one (MIC of $2.0 \mu \mathrm{g} / \mathrm{mL}$ ) [151]. The antimycobacterial activity of (E)-phytol and of some 24,25-epoxycycloartanes have previously been reported by Cantrell et al. [152].

\subsubsection{In vivo studies}

\subsubsection{Immunostimulatory activity and nutraceutical value}

The juice from noni fruits is commercially sold as a health tonic which consumption has dramatically increased, recently [153]. Partly because of radical scavenging activity and immunity 
enhancing properties of noni, it is considered as a promising functional food which immunoadjunctive effects [154,155]. The water extract of $M$. citrifolia fruits revealed its immunostimulatory effects in vitro, ex vivo and in vivo by activating both innate and adaptive immune responses in healthy mice [156].

Noni has been known for over 2000 years by the natives of Polynesia as a nutritional agent used to treat diseases and maintain health. Due to a high amount of micronutrients, vitamin A, C, sugars and fiber, $M$. citrifolia fruit is suggested to promote general good health and to be beneficial for physical activity [157]. The study were the mice swimming model was used, revealed that noni leaves water extract may alleviate fatigue [158]. In M. citrifolia treated group the improvement of the blood glucose, nutrient and lactate levels was observed. Noni helped to combat exhaustion by enhancing energy production. This findings may be crucial in infectious disease recovery. Morina citrifolia may be regarded as an adjuvant used in anti-tuberculosis therapy [158].

\subsection{Piperaceae Family}

Piper nigrum L., black pepper, is a herb of the Piperaceae family, native to tropical, Indo-Malaya region. It is regarded as "the king of spices" and generally used in almost every cuisine [159]. The black pepper has an essential role in the traditional Indian system of medicine, called 'Ayurveda' where it has been used as a basis of medicinal formulations recommended in the treatment of various infectious diseases such as leprosy or tuberculosis $[160,161]$. The wide spectrum of pharmacological activities of black pepper, including antimicrobial, antifungal and anti-inflammatory are related to the presence of various phytoconstituents, but primarily, alkaloid - piperine [162-164]. In the recent years, therapeutic potential of different Piper taxons, piper extracts and piperine was described in a number of research.

\subsubsection{In vitro antimycobacterial activity}

Numerous studies have been focused on the therapeutic potential of different members of the Piperaceae family. Plants belonging to the Piper genus may produce various secondary metabolites such as alkaloids, flavonoids, phenylpropanoids, lignans, benzenoids, steroids, monoterpenoids and essential oils [165], which may be involved in antimycobacterial effects. According to Diaz et al. [166] high polyphenols content was associated with the antimycobacterial activity of the flower extract of Piper imperiale which was reported to inhibit the growth of Mtb H37Rv at $75 \mu \mathrm{g} / \mathrm{mL}$. Chen et al. [167] evaluated the potential antitubercular activity of neolignans and phenylpropanoids found in the methanolic extracts of the roots of Piper taiwanense. The most effective in inhibition of Mtb H37Rv were: hydroxychavicol acetate (MIC of $30.3 \mu \mathrm{g} / \mathrm{mL}$ ), 4-allylcatechol (MIC of $27.6 \mu \mathrm{g} / \mathrm{mL}$ ), and trans-caffeicaldehyde (MIC of $25.5 \mu \mathrm{g} / \mathrm{mL}$ ). Further analysis of the root phytoconstituents revealed the presence of other compounds, obtained as two isomer mixtures of taiwanensols $\mathrm{A}$ and $\mathrm{B}$, and taiwanensol $\mathrm{C}$ and 3-acetoxy-4-hydroxy-1-allylbenzene with inhibitory effect against Mtb bacilli at MIC of 30.0 and $48.0 \mu \mathrm{g} / \mathrm{mL}$, respectively [165]. Also a benzoic acid derivatives isolated from supercritical $\mathrm{CO}_{2}\left(\mathrm{SFE}-\mathrm{CO}_{2}\right)$ extracts of Piper diospyrifolium leaves were reported by Regiane et al. [168] to demonstrate a moderate antimycobacterial activity (MIC of $125 \mu \mathrm{g} / \mathrm{mL}$ ). The neolignan, eupomatenoid-5, identified in SFE-CO ${ }_{2}$ extract derived from leaves of Piper regnellii, was shown to inhibit the growth of Mtb H37Rv at $1.9 \mu \mathrm{g} / \mathrm{mL}$ [169]. According to Lopes et al., eupomatenoid-5 may be a promising agent in multidrug therapy. When used in combination with first-line anti-TB drugs it revealed synergistic effects against Mtb H37Rv [170].

\subsubsection{In vivo studies}

\subsubsection{Antimycobacterial and immunomodulatory activity}

Due to the chemical structure different from anti-TB drugs, piperine is considered as a privileged scaffold for the development of new, bioactive drug molecules with less resistance and toxicity $[171,172]$. It was shown to enhance the bioavailability of several drugs and to act in synergy with them [38,173]. Piperine coadministration with rifampicin $(10 \mathrm{mg} / \mathrm{kg})$ exhibited a greater reduction of Mtb bacilli load in animals lung tissue within 4 weeks as compared with rifampicin alone. Moreover, piperine demonstrated the immunomodulatory effects via up-regulation of Th-1 immune response in mouse splenocytes [38]. What is more, according to Amaral et al. [174], piperine may be considered as a compound enhancing the killing of MDR Mtb strains through inhibition of pathogen's P-glycoprotein, which expression is related to the promotion of bacilli's tolerance toward anti-TB drugs.

\subsection{Nigella sativa L.}

Black cumin is widely known as a spice used for flavouring of bakery products, pickles, sauces, and salads. It originates from Middle East, Middle Asia and Far Eastern countries where it was considered by earliest herbal specialists as miraculous plant. The medicinal uses of black cumin seeds range from airway disorders, fever, coughs, infection, pain, or inflammation to paralysis [175]. The pharmacological effects: analgesic, anticancer, antidiabetic, antihypertensive, anti-inflammatory, antimicrobial, antioxidant and neuroprotective, exerted by $N$. sativa seeds, seeds fixed oil and essential oil are attributed to the most bioactive compound, thymoquinone [175].

\subsubsection{In vitro antimycobacterial activity}

Thymoquinone was shown to inhibit the growth of clinical isolates of $\mathrm{Mtb}$ in vitro in a dose higher than $20 \mu \mathrm{g} / \mathrm{mL}$ [176]. It was also proven to inhibit the replication of intracellular Mtb in RAW 264.7 macrophages at concentrations ranging from 12.5 to $25 \mu \mathrm{g} / \mathrm{mL}$ and 6.25 to $12.5 \mu \mathrm{g} / \mathrm{mL}$ for $\mathrm{H} 37 \mathrm{Rv}$ and XDR-TB strains, respectively [177]. The killing of the bacilli in the presence of thymoquinone was mediated via concentration-dependent reduction in NO production in both H37Rv and XDR-TB infected RAW 264.7 cells. What is more, the lowered expression of iNOS, TNF- $\alpha$ and IL-6 was observed in H37Rv-infected cells resulting in reduced pathogen-derived stress in host cells [177].

\subsubsection{In vivo studies}

\subsubsection{Hepatoprotective activity}

Nigella sativa and thymoquinone were also studied for their hepatoprotective potential against anti-TB drugs induced liver injury 
[178-181]. The introduction of thymoquinone or N. sativa to the treatment after administration of antibiotics, normalized the levels of AST, ALT, ALP, bilirubin, albumin, cholesterol, urea, uric acid, creatinine and antioxidant enzymes (superoxide dismutase) in rats. Histopathological examinations of liver showed improved cellular architecture. The authors suggested that membrane stabilizing effect exerted by thymoquinone may be related to decreased oxidative stress and free radical mediated tissue damage $[178,179]$. Similar beneficial effects of administration of black cumin oil after isoniazid treatment were observed by Paul et al. A significant reduction in the liver enzymes (AST, ALT, ALP) and total bilirubin levels as well as significant improvement in the microscopic architecture of the liver were obtained in rats treated with oil when compared with control group. Again, authors explained that the hepatoprotective effects of the oil is due to the presence of thymoquinone and its antioxidant and anti-inflammatory activities [181]. Nigella sativa suspension co-administered with pyrazinamide alone or with combination of pyrazinamide, isoniazid and rifampicin was studied for hepatoprotection in rabbits as well. Combined therapy resulted in significantly improved liver enzymes, glutathione $S$-transferase, MDA and histopathological changes toward normal values [180]. Taken together, the presented literature data indicate protective effect of black cumin against liver damage in TB treatment, mainly due to antioxidant and anti-inflammatory effects.

\subsubsection{Nutraceutical value}

The additional value of black cumin supplementation during TB management may be its nutrient-rich composition. The high nutritional value of seeds is related to the presence of protein, fat, fiber, and carbohydrates. Besides various amino acids, $N$. sativa seeds contain iron, copper, zinc, phosphorus, calcium, thiamin, niacin, pyridoxine, and folic acid [175], which are important during TB treatment. Especially, the administration of zinc, iron and copper were shown to boost host defence functions against $\mathrm{Mtb}$, due to better lymphocyte proliferation and immune responses, when administered as adjuvant to MDR-TB therapy [75,77].

\section{CONCLUDING REMARKS}

The usefulness of plants in fighting tuberculosis is not limited to reservoir of antimycobacterial drug leads. The data discussed above suggest that plants may be potential adjunct agents reducing side effects of classical antimycobacterial antibiotics, protecting the liver from anti-TB drug-induced liver injury, restoring the balance between the inflammatory and anti-inflammatory processes disrupted by bacilli, and nourishing of the exhausted organism. The beneficial effects of co-administration of some plant-derived food products with classical anti-TB therapy was supported by clinical trials, however, more scientific evidence is needed to fully explore numerous plant species used by traditional healers to manage tuberculosis. Undoubtedly, the introduction of herbal drugs and dietary supplements may shorten the TB treatment and should be recommended in anti-TB regimen.

\section{CONFLICTS OF INTEREST}

The authors declare they have no conflicts of interest.

\section{AUTHORS' CONTRIBUTION}

ES designed and review; ES and MMT contributed to data collection, analysis and writing, ES prepared the manuscript; LS and JX revised the manuscript.

\section{REFERENCES}

[1] World Health Organization. Global tuberculosis report 2019. Geneva: World Health Organization; 2019.

[2] Cernuschi T, Malvolti S, Nickels E, Friede M. Bacillus CalmetteGuérin (BCG) vaccine: a global assessment of demand and supply balance. Vaccine 2018;36:498-506.

[3] Shehzad A, Rehman G, Ul-Islam M, Khattak WA, Lee YS. Challenges in the development of drugs for the treatment of tuberculosis. Braz J Infect Dis 2013;17:74-81.

[4] Donoghue HD, Spigelman M, Greenblatt CL, Lev-Maor G, Bar-Gal GK, Matheson C, et al. Tuberculosis: from prehistory to Robert Koch, as revealed by ancient DNA. Lancet Infect Dis 2004;4:584-92.

[5] Barberis I, Bragazzi NL, Galluzzo L, Martini M. The history of tuberculosis: from the first historical records to the isolation of Koch's bacillus. J Prev Med Hyg 2017;58:E9-E12.

[6] Gray CA, Johnson JA, Webster D. Canadian traditionally used medicinal plants: can they play a role in antituberculosis drug development? Future Med Chem 2013;5:853-5.

[7] Madikizela B, Kambizi L, McGaw LJ. An ethnobotanical survey of plants used traditionally to treat tuberculosis in the eastern region of O.R. Tambo district, South Africa. S Afr J Bot 2017;109:231-6.

[8] Green E, Samie A, Obi CL, Bessong PO, Ndip RN. Inhibitory properties of selected South African medicinal plants against Mycobacterium tuberculosis. J Ethnopharmacol 2010;130:151-7.

[9] Lawal IO, Grierson DS, Afolayan AJ. Phytotherapeutic information on plants used for the treatment of tuberculosis in Eastern Cape Province, South Africa. Evid Based Complement Alternat Med. 2014;2014:735423.

[10] Semenya SS, Maroyi A. Ethnobotanical survey of plants used by Bapedi traditional healers to treat tuberculosis and its opportunistic infections in the Limpopo Province, South Africa. S Afr J Bot 2019;122:401-21.

[11] Bunalema L, Obakiro S, Tabuti JR, Waako P. Knowledge on plants used traditionally in the treatment of tuberculosis in Uganda. J Ethnopharmacol 2014;151:999-1004.

[12] Nguta JM, Appiah-Opong R, Nyarko AK, Yeboah-Manu D, Addo PG. Medicinal plants used to treat TB in Ghana. Int J Mycobacteriol 2015;4:116-23.

[13] Mohamad S, Zin NM, Wahab HA, Ibrahim P, Sulaiman SF, Zahariluddin AS, et al. Antituberculosis potential of some ethnobotanically selected Malaysian plants. J Ethnopharmacol 2011;133:1021-6.

[14] Gupta VK, Kaushik A, Chauhan DS, Ahirwar RK, Sharma S, Bisht D. Anti-mycobacterial activity of some medicinal plants used traditionally by tribes from Madhya Pradesh, India for treating tuberculosis related symptoms. J Ethnopharmacol 2018;227:113-20.

[15] Sharma A, Flores-Vallejo RDC, Cardoso-Taketa A, Villarreal ML. Antibacterial activities of medicinal plants 
used in Mexican traditional medicine. J Ethnopharmacol 2017;208:264-329.

[16] Gómez-Cansino R, Guzmán-Gutiérrez SL, Campos-Lara MG, Espitia-Pinzón CI, Reyes-Chilpa R. Natural compounds from Mexican medicinal plants as potential drug leads for antituberculosis drugs. An Acad Bras Cienc 2017;89:31-43.

[17] McGaw LJ, Lall N, Meyer JJ, Eloff JN. The potential of South African plants against Mycobacterium infections. J Ethnopharmacol 2008;119:482-500.

[18] Bueno-Sánchez JG, Martínez-Morales JR, Stashenko EE, Ribón W. Anti-tubercular activity of eleven aromatic and medicinal plants occurring in Colombia. Biomedica 2009;29:51-60.

[19] Duke T, Kasa Tom S, Poka H, Welch H. Holistic care of complicated tuberculosis in healthcare settings with limited resources. Arch Dis Child 2017;102:1161-8.

[20] Chinsembu KC. Tuberculosis and nature's pharmacy of putative anti-tuberculosisagents. Acta Trop 2016;153:46-56.

[21] Semenya SS, Maroyi A. Medicinal plants used for the treatment of tuberculosis by Bapedi traditional healers in three districts of the Limpopo Province, South Africa. Afr J Tradit Complement Altern Med 2013;10:316-23.

[22] Newton SM, Lau C, Wright CW. A review of antimycobacterial natural products. Phytother Res 2000;14:303-22.

[23] Pandit R, Singh PK, Kumar V. Natural remedies against multi-drug resistant Mycobacterium tuberculosis. J Tuberc Res 2015;3:171-83.

[24] Tosun F, Akyüz Kızılay Ç, Şener B, Vural M. The evaluation of plants from Turkey for in vitro. antimycobacterial activity. Pharm Biol 2005;43:58-63.

[25] Buszczyński S. Opis 125 ziół używanych w lecznictwie z podaniem ich uprawy i zastosowania. Berlin: "Przewodnik Zdrowia"; 1912.

[26] Wang M, Guan X, Chi Y, Robinson N, Liu JP. Chinese herbal medicine as adjuvant treatment to chemotherapy for multidrug-resistant tuberculosis (MDR-TB): a systematic review of randomised clinical trials. Tuberculosis (Edinb) 2015;95:364-72.

[27] Gupta VK, Kumar MM, Bisht D, Kaushik A. Plants in our combating strategies against Mycobacterium tuberculosis: progress made and obstacles met. Pharm Biol 2017;55:1536-44.

[28] Deshmukh SK, Verekar SA, Bhave SV. Endophytic fungi: a reservoir of antibacterials. Front Microbiol 2015;5:715.

[29] Shah A, Rather MA, Hassan QP, Aga MA, Mushtaq S, Shah AM, et al. Discovery of anti-microbial and anti-tubercular molecules from Fusarium solani: an endophyte of Glycyrrhiza glabra. J Appl Microbiol 2017;122:1168-76.

[30] Polak Z, Kapka-Skrzypczak L. Anti-tubercular substances produced by plants. J Pre-Clin Clin Res 2017;11:147-52.

[31] Komape NPM, Bagla VP, Kabongo-Kayoka P, Masoko P. Antimycobacteria potential and synergistic effects of combined crude extracts of selected medicinal plants used by Bapedi traditional healers to treat tuberculosis related symptoms in Limpopo Province, South Africa. BMC Complement Altern Med 2017;17:128.

[32] Fauziyah PN, Sukandar EY, Ayuningtyas DK. Combination effect of antituberculosis drugs and ethanolic extract of selected medicinal plants against multi-drug resistant Mycobacterium tuberculosis isolates. Sci Pharm 2017;85:14.

[33] Sieniawska E, Sawicki R, Swatko-Ossor M, Napiorkowska A, Przekora A, Ginalska G, et al. The effect of combining natural terpenes and antituberculous agents against reference and clinical Mycobacterium tuberculosis strains. Molecules 2018;23:176.
[34] Guo N, Wu J, Fan J, Yuan P, Shi Q, Jin K, et al. In vitro activity of isoimperatorin, alone and in combination, against Mycobacterium tuberculosis. Lett Appl Microbiol 2014;58:344-9.

[35] Nam KW, Jang WS, Jyoti MA, Kim S, Lee BE, Song HY. In vitro activity of (-)-deoxypergularinine, on its own and in combination with anti-tubercular drugs, against resistant strains of Mycobacterium tuberculosis. Phytomedicine 2016;23:578-82.

[36] Covic A, Goldsmith DJ, Segall L, Stoicescu C, Lungu S, Volovat C, et al. Rifampicin-induced acute renal failure: a series of 60 patients. Nephrol Dial Transplant 1998;13:924-9.

[37] Nageswari AD, Rajanandh MG, Uday MKRA, Nasreen RJ, Pujitha RR, Prathiksha G. Effect of rifampin with bio-enhancer in the treatment of newly diagnosed sputum positive pulmonary tuberculosis patients: a double-center study. J Clin Tuberc Other Mycobact Dis 2018;12:73-7.

[38] Sharma S, Kalia NP, Suden P, Chauhan PS, Kumar M, Ram AB, et al. Protective efficacy of piperine against Mycobacterium tuberculosis. Tuberculosis (Edinb) 2014;94:389-96.

[39] Yang TW, Park HO, Jang HN, Yang JH, Kim SH, Moon SH, et al. Side effects associated with the treatment of multidrug-resistant tuberculosis at a tuberculosis referral hospital in South Korea. A retrospective study. Medicine (Baltimore) 2017;96:e7482.

[40] Babalık A, Arda H, Bakırcı N, Ağca S, Oruç K, Kızıltaş S, et al. Management of and risk factors related to hepatotoxicity during tuberculosis treatment. Tüberk Toraks 2012;60:136-44.

[41] Ramappa V, Aithal GP. Hepatotoxicity related to anti-tuberculosis drugs: mechanisms and management. J Clin Exp Hepatol 2013;3:37-49.

[42] Luangchosiri C, Thakkinstian A, Chitphuk S, Stitchantrakul W, Petraksa S, Sobhonslidsuk A. A double-blinded randomized controlled trial of silymarin for the prevention of antituberculosis drug-induced liver injury. BMC Complement Altern Med 2015;15:334.

[43] Marjani M, Baghaei P, Kazempour Dizaji M, Gorji Bayani P, Fahimi F, Tabarsi P, et al. Evaluation of hepatoprotective effect of silymarin among under treatment tuberculosis patients: a randomized clinical trial. Iran J Pharm Res 2016;15:247-52.

[44] Diallo T, Adjobimey M, Ruslami R, Trajman A, Sow O, Obeng Baah J, et al. Safety and side effects of rifampin versus isoniazid in children. N Engl J Med 2018;379:454-63.

[45] Mangwani N, Singh PK, Kumar V. Medicinal plants: adjunct treatment to tuberculosis chemotherapy to prevent hepatic damage. J Ayurveda Integr Med 2019 (In Press).

[46] Chowdhury A, Santra A, Kundu S, Mukherjee A, Pandit A, Chaudhuri S, et al. Induction of oxidative stress in antitubercular drug-induced hepatotoxicity. Indian J Gastroenterol 2001;20:97-100.

[47] Vuilleumier N, Rossier MF, Chiappe A, Degoumois F, Dayer P, Mermillod B, et al. CYP2E1 genotype and isoniazid-induced hepatotoxicity in patient treated for latent tuberculosis. Eur J Clin Pharmacol 2006;62:423-9.

[48] Nasiru A, Hafsat IG, Mohammad MM, Sabo AA. Hepatoprotective effect of garlic homogenate co-administered with antituberculosis drugs in rat liver enzymes. Int J Biosci Biochem Bioinform 2012;2:354-7.

[49] Sana T, Javed I, Aamir A. Antituberculous treatment induced ALT and ALP derangements and the role of onion extract in male albino Rats. Ann Punjab Med Coll 2010;4:33-8.

[50] Tasduq SA, Singh K, Satti NK, Gupta DK, Suri KA, Johri RK. Terminalia chebula (fruit) prevents liver toxicity caused by 
sub-chronic administration of rifampicin, isoniazid and pyrazinamide in combination. Hum Exp Toxicol 2006;25:111-8.

[51] Eminzade S, Uraz F, Izzettin FV. Silymarin protects liver against toxic effects of anti-tuberculosis drugs in experimental animals. Nutr Metab (Lond) 2008;5:18.

[52] Jahan S, Khan M, Imran S, Sair M. The hepatoprotective role of Silymarin in isoniazid induced liver damage of rabbits. J Pak Med Assoc 2015;65:620-2.

[53] Tousif S, Singh DK, Mukherjee S, Ahmad S, Arya R, Nanda R, et al. Nanoparticle-formulated curcumin prevents posttherapeutic disease reactivation and reinfection with Mycobacterium tuberculosis following isoniazid therapy. Front Immunol 2017;8:739.

[54] Tsai CW, Chen HW, Yang JJ, Sheen LY, Lii CK. Diallyl disulfide and diallyl trisulfide up-regulate the expression of the pi class of glutathione S-transferase via an AP-1-dependent pathway. J Agric Food Chem 2007;55:1019-26.

[55] Oosthuizen C, Arbach M, Meyer D, Hamilton C, Lall N. Diallyl polysulfides from allium sativum as immunomodulators, hepatoprotectors, and antimycobacterial agents. J Med Food 2017;20:685-90.

[56] Sia JK, Rengarajan J. Immunology of Mycobacterium tuberculosis infections. Microbiol Spectr 2019;7:GPP3-0022-2018.

[57] Hawn TR, Matheson AI, Maley SN, Vandal O. Host-directed therapeutics for tuberculosis: can we harness the host? Microbiol Mol Biol Rev 2013;77:608-27.

[58] Joshi L, Ponnana M, Sivangala R, Chelluri LK, Nallari P, Valluri VL, et al. Cytokine production and mRNA expression in pulmonary tuberculosis patients and their household contacts of younger age group (15-25years). J Immunol Methods 2016;432:65-71.

[59] Rahman MA, Sobia P, Dwivedi VP, Bhawsar A, Singh DK, Sharma $\mathrm{P}$, et al. Mycobacterium tuberculosis TlyA negatively regulates $\mathrm{T}$ Helper (Th) 1 and Th17 differentiation and promotes tuberculosis pathogenesis. J Biol Chem 2015;290:14407-17.

[60] den Boon S, van Lill SW, Borgdorff MW, Enarson DA, Verver $\mathrm{S}$, Bateman ED, et al. High prevalence of tuberculosis in previously treated patients, Cape Town, South Africa. Emerg Infect Dis 2007;13:1189-94.

[61] Tousif S, Singh DK, Ahmad S, Moodley P, Bhattacharyya M, Van Kaer L, et al. Isoniazid induces apoptosis of activated CD4+ T cells: implications for post-therapy tuberculosis reactivation and reinfection. J Biol Chem 2014;289:30190-5.

[62] van Rie A, Warren R, Richardson M, Victor TC, Gie RP, Enarson DA, et al. Exogenous reinfection as a cause of recurrent tuberculosis after curative treatment. $\mathrm{N}$ Engl J Med 1999;341:1174-9.

[63] Friedman ND, McDonald AH, Robson ME, O’Brien DP. Corticosteroid use for paradoxical reactions during antibiotic treatment for Mycobacterium ulcerans. PLoS Negl Trop Dis 2012;6:e1767.

[64] Pakadang SR, Wahjuni CU, Notobroto HB, Winarni D, Dwiyanti $\mathrm{R}$, Yadi, et al. Immunomodulator potential of miana leaves (Coleus scutellarioides (L) Benth) in prevention of tuberculosis infection. Am J Microbiol Res 2015;3:129-34.

[65] Dwivedi VP, Bhattacharya D, Singh M, Bhaskar A, Kumar $\mathrm{S}$, Sobiae P, et al. Allicin enhances antimicrobial activity of macrophages during Mycobacterium tuberculosis infection. J Ethnopharmacol 2019;243:111634.

[66] Rodríguez-Flores EM, Mata-Espinosa D, Barrios-Payan J, Marquina-Castillo B, Castañón-Arreola M, Hernández-Pando R. A significant therapeutic effect of silymarin adminis- tered alone, or in combination with chemotherapy, in experimental pulmonary tuberculosis caused by drug-sensitive or drug-resistant strains: in vitro and in vivo studies. PLoS One 2019;14:e0217457.

[67] Putri DU, Rintiswati N, Soesatyo MH, Haryana SM. Immune modulation properties of herbal plant leaves: Phyllanthus niruri aqueous extract on immune cells of tuberculosis patient - in vitro study. Nat Prod Res 2018;32:463-7.

[68] Amin Z. The role of Phyllanthus niruri extract as an add-on therapy to the standard regimens of tuberculosis in patients with minimal or moderate radiological tuberculosis-lesion. Jakarta: University of Indonesia; 2005.

[69] Raveinal R. The effect of natural immunomodulator (Phyllanti herb extract) administration on cellular immune response of patients with pulmonary tuberculosis. Padang: University of Andalas; 2003.

[70] Aro AO, Dzoyem JP, Goddard A, Fonteh P, Kayoka-Kabongo $\mathrm{PN}, \mathrm{McGaw}$ LJ. In vitro antimycobacterial, apoptosis-inducing potential, and immunomodulatory activity of some Rubiaceae species. Front Pharmacol 2019;10:185.

[71] Gupta PK, Chakraborty P, Kumar S, Singh PK, Rajan MG, Sainis KB, et al. G1-4A, a polysaccharide from Tinospora cordifolia inhibits the survival of Mycobacterium tuberculosis by modulating host immune responses in TLR4 dependent manner. PLoS One 2016;11:e0154725.

[72] Xu HD, You CG, Zhang RL, Gao P, Wang ZR. Effects of Astragalus polysaccharides and astragalosides on the phagocytosis of Mycobacterium tuberculosis by macrophages. J Int Med Res 2007;35:84-90.

[73] Bai X, Oberley-Deegan RE, Bai A, Ovrutsky AR, Kinney WH, Weaver $\mathrm{M}$, et al. Curcumin enhances human macrophage control of Mycobacterium tuberculosis infection. Respirology 2016;21:951-7.

[74] Yamamoto Y, Gaynor RB. Therapeutic potential of inhibition of the NF- $\kappa \mathrm{B}$ pathway in the treatment of inflammation and cancer. J Clin Invest 2001;107:135-42.

[75] Gupta KB, Gupta R, Atreja A, Verma M, Vishvkarma S. Tuberculosis and nutrition. Lung India 2009;26:9-16.

[76] Cegielski JP, McMurray DN. The relationship between malnutrition and tuberculosis: evidence from studies in humans and experimental animals. Int J Tuberc Lung Dis 2004;8:286-98.

[77] Chandrasekaran P, Saravanan N, Bethunaickan R, Tripathy S. Malnutrition: modulator of immune responses in tuberculosis. Front Immunol 2017;8:1316.

[78] Fox GJ, Lee RS, Lucas M, Khan FA, Proulx JF, Hornby K, et al. Inadequate diet is associated with acquiring mycobacterium tuberculosis infection in an Inuit community. a case-control study. Ann Am Thorac Soc 2015;12:1153-62.

[79] Baj T, Sieniawska E. Vitamins. In: Badal SM, Delgoda R, editors. Pharmacognosy: fundamentals, applications and strategies. Boston: Academic Press; 2017, pp. 281-92.

[80] Samuel B, Volkmann T, Cornelius S, Mukhopadhay S, MejoJose, Mitra K, et al. Relationship between nutritional support and tuberculosis treatment outcomes in west Bengal, India. J Tuberc Res 2016;4:213-9.

[81] Mel'nyk VP, Anisimova IuM, Borovs'kyı̆ VR, Stadnyk LV, Svitlychna TH. [Soy-based food in a complex treatment of patients with tuberculosis]. Lik Sprava 2006;8:65-70.

[82] Jantan I, Ahmad W, Bukhari SNA. Plant-derived immunomodulators: an insight on their preclinical evaluation and clinical trials. Front Plant Sci 2015;6:655. 
[83] Nair KP. Pharmacology and nutraceutical uses of ginger. Turmeric (Curcuma longa L.) and Ginger (Zingiber officinale Rosc.) - world's invaluable medicinal spices. Cham: Springer Nature; 2019, pp. 519-39.

[84] Shahrajabian MH, Sun W, Cheng Q. Pharmacological uses and health benefits of ginger (Zingiber officinale) in traditional Asian and ancient Chinese medicine, and modern practice. Not Sci Biol 2019;11:309-19.

[85] Maroyi A. Alternative medicines for HIV/AIDS in resource-poor settings: insight from traditional medicines use in sub-Saharan Africa. Trop J Pharm Res 2014;13:1527-36.

[86] Nguta JM, Appiah-Opong R, Nyarko AK, Yeboah-Manu D, Addo PG, Otchere I, et al. Antimycobacterial and cytotoxic activity of selected medicinal plant extracts. J Ethnopharmacol 2016;182:10-15.

[87] Mohd Sahardi NFN, Makpol S. Ginger (Zingiber officinale Roscoe) in the prevention of ageing and degenerative diseases: review of current evidence. Evid Based Complement Alternat Med 2019;2019:5054395.

[88] Del Carmen Beristain-Bauza S, Hernández-Carranza P, CidPérez TS, Ávila-Sosa R, Ruiz-López II, Ochoa-Velasco CE. Antimicrobial activity of ginger (Zingiber officinale) and its application in food products. Food Rev Int 2019;35:407-26.

[89] Baldin VP, Bertin de Lima Scodro R, Mariano Fernandez CM, Ieque AL, Caleffi-Ferracioli KR, Dias Siqueira VL, et al. Ginger essential oil and fractions against Mycobacterium spp. J Ethnopharmacol 2019;244:112095.

[90] Hiserodt RD, Franzblau SG, Rosen RT. Isolation of 6-, 8-, and 10-gingerol from ginger rhizome by hplc and preliminary evaluation of inhibition of Mycobacterium avium and Mycobacterium tuberculosis. J Agric Food Chem 1998;46:2504-8.

[91] Aguinaldo AM. Selected Zingiberaceae species exhibiting inhibitory activity against Mycobacterium tuberculosis H37Rv: a phytochemical profile. Gardens Bull, Singapore 2007;59:13-21.

[92] Kulkarni RA, Deshpande AR. Anti-inflammatory and antioxidant effect of ginger in tuberculosis. J Complement Integr Med 2016;13:201-6.

[93] Pan MH, Hsieh MC, Kuo JM, Lai CS, Wu H, Sang S, et al. 6-Shogaol induces apoptosis in human colorectal carcinoma cells via ROS production, caspase activation, and GADD 153 expression. Mol Nutr Food Res 2008;52:527-37.

[94] Tjendraputra E, Tran VH, Liu-Brennan D, Roufogalis BD, Duke CC. Effect of ginger constituents and synthetic analogues on cyclooxygenase-2 enzyme in intact cells. Bioorg Chem 2001;29:156-63.

[95] Verma SK, Singh M, Jain P, Bordia A. Protective effect of ginger, Zingiber officinale Rosc on experimental atherosclerosis in rabbits. Indian J Exp Biol 2004;42:736-8.

[96] Wang ML, Yang YL, Wei ZX, Yue W, Xu WQ. The effect of gingerol on cisplatin-induced pica in rats. Chin Pharmacol Bull 2012;28:558-62.

[97] Semwal RB, Semwal DK, Combrinck S, Viljoen AM. Gingerols and shogaols: important nutraceutical principles from ginger. Phytochemistry 2015;117:554-68.

[98] Kumar S, Singh UN, Saxena K. Synergestic effect of ginger extract in pulmonary tuberculosis patients. Int J Contemp Med Res 2017;4:1468-70.

[99] Baldwin PR, Reeves AZ, Powell KR, Napier RJ, Swimm AI, Sun A, et al. Monocarbonyl analogs of curcumin inhibit growth of antibiotic sensitive and resistant strains of Mycobacterium tuberculosis. Eur J Med Chem 2015;92:693-9.
[100] Kunnumakkara AB, Bordoloi D, Padmavathi G, Monisha J, Roy NK, Prasad S, et al. Curcumin, the golden nutraceutical: multitargeting for multiple chronic diseases. Br J Pharmacol 2017; 174:1325-48.

[101] Prasad S, Gupta SC, Tyagi AK, Aggarwal BB. Curcumin, a component of golden spice: from bedside to bench and back. Biotechnol Adv 2014;32:1053-64.

[102] Kocaadam B, Şanlier N. Curcumin, an active component of turmeric (Curcuma longa), and its effects on health. Crit Rev Food Sci Nutr 2017;57:2889-95.

[103] Huang L, Chen C, Zhang X, Li X, Chen Z, Yang C, et al. Neuroprotective effect of curcumin against cerebral ischemiareperfusion via mediating autophagy and inflammation. J Mol Neurosci 2018;64:129-39.

[104] Li H, Sureda A, Devkota HP, Pittalà V, Barreca D, Silva AS, et al. Curcumin, the golden spice in treating cardiovascular diseases. Biotechnol Adv 2020;38:107343.

[105] Gupta SC, Kismali G, Aggarwal BB. Curcumin, a component of turmeric: from farm to pharmacy. Biofactors 2013;39:2-13.

[106] Naik SR, Thakare VN, Patil SR. Protective effect of curcumin on experimentally induced inflammation, hepatotoxicity and cardiotoxicity in rats: evidence of its antioxidant property. Exp Toxicol Pathol 2011;63:419-31.

[107] He Y, Yue Y, Zheng X, Zhang K, Chen S, Du Z. Curcumin, inflammation, and chronic diseases: how are they linked? Molecules 2015;20:9183-213.

[108] Catanzaro M, Corsini E, Rosini M, Racchi M, Lanni C. Immunomodulators inspired by nature: a review on curcumin and echinacea. Molecules 2018;23:2778.

[109] Zhao C, Liu Z, Liang G. Promising curcumin-based drug design: mono-carbonyl analogues of curcumin (MACs). Curr Pharm Des 2013;19:2114-35.

[110] Zhang Y, Zhao C, He W, Wang Z, Fang Q, Xiao B, et al. Discovery and evaluation of asymmetrical monocarbonyl analogs of curcumin as anti-inflammatory agents. Drug Des Devel Ther 2014; 4:373-82.

[111] Agrawal DK, Saikia D, Tiwari R, Ojha S, Shanker K, Kumar JK, et al. Demethoxycurcumin and its semisynthetic analogues as antitubercular agents. Planta Med 2008;74:1828-31.

[112] Changtam C, Hongmanee P, Suksamrarn A. Isoxazole analogs of curcuminoids with highly potent multidrug-resistant antimycobacterial activity. Eur J Med Chem 2010;45:4446-57.

[113] Karuppagounder V, Arumugam S, Thandavarayan RA, Sreedhar R, Giridharan VV, Afrin R, et al. Curcumin alleviates renal dysfunction and suppresses inflammation by shifting from M1 to M2 macrophage polarization in daunorubicin induced nephrotoxicity in rats. Cytokine 2016;94:1-9.

[114] Abdollahi E, Momtazi AA, Johnston TP, Sahebkar A. Therapeutic effects of curcumin in inflammatory and immune-mediated diseases: a nature-made jack-of-all-trades? J Cell Physiol 2018; 233:830-48.

[115] Karbalaei M, Keikha M. The curcumin effects on immuneresponse and its potential properties against tuberculosis. JSM Clin Cytol Pathol 2019;4:4.

[116] Liu W, Zhai Y, Heng X, Che FY, Chen W, Sun D, et al. Oral bioavailability of curcumin: problems and advancements. J Drug Target 2016;24:694-702.

[117] Ahmad S, Bhattacharya D, Kar S, Ranganathan A, Van Kaer L, Das G. Curcumin nanoparticles enhance Mycobacterium bovis BCG vaccine efficacy by modulating host immune responses. Infect Immun 2019;87:e00291-e319. 
[118] Song Z, Deaciuc I, Song M, Lee DY, Liu Y, Ji X, et al. Silymarin protects against acute ethanol-induced hepatotoxicity in mice. Alcohol Clin Exp Res 2006;30:407-13.

[119] Comelli MC, Mengs U, Schneider C, Prosdocimi M. Toward the definition of the mechanism of action of silymarin: activities related to cellular protection from toxic damage induced by chemotherapy. Integr Cancer Ther 2007;6:120-9.

[120] Mengs U, Pohl RT, Mitchell T. Legalon ${ }^{\circledR}$ SIL: the antidote of choice in patients with acute hepatotoxicity from amatoxin poisoning. Curr Pharm Biotechnol 2012;13:1964-70.

[121] Sheng YK, Zhang L, Hong Y. Silymarin in preventing antituberculosis and antipsychotic drug-induced liver injury at different doses and treatment times: a systematic review. Iran Red Crescent Med J 2019;21:e94743.

[122] Hogan FS, Krishnegowda NK, Mikhailova M, Kahlenberg MS. Flavonoid, silibinin, inhibits proliferation and promotes cellcycle arrest of human colon cancer. J Surg Res 2007;14:58-65.

[123] Tasduq SA, Peerzada K, Koul S, Bhat R, Johri RK. Biochemical manifestations of anti-tuberculosis drugs induced hepatotoxicity and the effect of silymarin. Hepatol Res 2005;31:132-5.

[124] Raghu R, Karthikeyan S. Zidovudine and isoniazid induced liver toxicity and oxidative stress: evaluation of mitigating properties of silibinin. Environ Toxicol Pharmacol 2016;46:217-26.

[125] Zhang S, Pan H, Peng X, Lu H, Fan H, Zheng X, et al. Preventive use of a hepatoprotectant against anti-tuberculosis druginduced liver injury: a randomized controlled trial. J Gastroenterol Hepatol 2016;31:409-16.

[126] Abenavoli L, Izzo AA, Milić N, Cicala C, Santini A, Capasso R. Milk thistle (Silybum marianum): a concise overview on its chemistry, pharmacological, and nutraceutical uses in liver diseases. Phytother Res 2018;32:2202-13.

[127] Zhang W, Hong R, Tian T. Silymarin's protective effects and possible mechanisms on alcoholic fatty liver for rats. Biomol Ther (Seoul). 2013;21:264-9.

[128] Liu GT. Bicyclol: a novel drug for treating chronic viral hepatitis B and C. Med Chem 2009;5:29-43.

[129] Chen S, Shi J, Zou L, Liu X, Tang R, Ma J, et al. Quality evaluation of wild and cultivated Schisandrae chinensis fructus based on simultaneous determination of multiple bioactive constituents combined with multivariate statistical analysis. Molecules 2019;24:1335.

[130] Winston D, Maimes S. Adaptogens: herbs for strength, stamina, and stress relief. Updated and Expanded. 2nd ed. Rochester: Healing Arts Press; 2019.

[131] Li F, Zhang T, Sun H, Gu H, Wang H, Su X, et al. A new nortriterpenoid, a sesquiterpene and hepatoprotective lignans isolated from the fruit of Schisandra chinensis. Molecules 2017;22:1931.

[132] Qiu F, Liu H, Duan H, Chen P, Lu SJ, Yang GZ, et al. Isolation, structural elucidation of three new triterpenoids from the stems and leaves of Schisandra chinensis (Turcz) Baill. Molecules 2018;23:1624.

[133] Mocan A, Crișan G, Vlase L, Crișan O, Vodnar DC, Raita O, et al. Comparative studies on polyphenolic composition, antioxidant and antimicrobial activities of Schisandra chinensis leaves and fruits. Molecules 2014;19:15162-79.

[134] Lu Y, Chen DF. Analysis of Schisandra chinensis and Schisandra sphenanthera. J Chromatogr A 2009;1216:1980-90.

[135] Hu J, Mao C, Gong X, Lu T, Chen H, Huang Z, et al. Simultaneous determination of eleven characteristic lignans in Schisandra chinensis by high-performance liquid chromatography. Pharmacogn Mag 2013;9:155-61.
[136] Szopa A, Ekiert R, Ekiert H. Current knowledge of Schisandra chinensis (Turcz.) Baill. (Chinese magnolia vine) as a medicinal plant species: a review on the bioactive components, pharmacological properties, analytical and biotechnological studies. Phytochem Rev 2017;16:195-218.

[137] Hwang IS, Kim JE, Lee YJ, Kwak MH, Choi YH, Kang BC, et al. Protective effects of gomisin A isolated from Schisandra chinensis against $\mathrm{CCl}(4)$-induced hepatic and renal injury. Int J Mol Med 2013;31:888-98.

[138] Yuan R, Tao X, Liang S, Pan Y, He L, Sun J, et al. Protective effect of acidic polysaccharide from Schisandra chinensis on acute ethanol-induced liver injury through reducing CYP2E1-dependent oxidative stress. Biomed Pharmacother 2018;99:537-42.

[139] Che J, Yang S, Qiao Z, Li H, Sun J, Zhuang W, et al. Schisandrachinensis acidic polysaccharide partialy reverses acetaminopheninduced liver injury in mice. J Pharmacol Sci 2019;140:248-54.

[140] Zhu P, Li J, Fu X, Yu Z. Schisandra fruits for the management of drug-induced liver injury in China: a review. Phytomedicine 2019;59:152760.

[141] Habibi P, Daniell H, Soccol CR, Grossi-de-Sa MF. The potential of plant systems to break the HIV-TB link. Plant Biotechnol J 2019;17:1868-91.

[142] Chen M, Kilgore N, Lee KH, Chen DF. Rubrisandrins A and B, lignans and related anti-HIV compounds from Schisandra rubriflora. J Nat Prod 2006;69:1697-701.

[143] Yang GY, Li YK, Wang RR, Xiao WL, Yang LM, Pu JX, et al. Dibenzocyclooctadiene lignans from the fruits of Schisandra wilsoniana and their anti-HIV-1 activities. J Asian Nat Prod Res 2010;12:470-6.

[144] Huang J, Ren L, Zhang S, Peng Z. Schisandra chinensis polysaccharides attenuate the growth of tuberculosis bacilli in rats via immunity enhancement. Trop J Pharm Res 2018;17:1651-5.

[145] Kortesoja M, Karhu E, Olafsdottir ES, Freysdottir J, Hanski L. Impact of dibenzocyclooctadiene lignans from Schisandra chinensis on the redox status and activation of human innate immune system cells. Free Radic Biol Med 2019;131:309-17.

[146] Chu NH, Li L, Zhang X, Gu J, Du YD, Cai C, et al. Role of bicyclol in preventing drug-induced liver injury in tuberculosis patients with liver disease. Int J Tuberc Lung Dis 2015; 19:475-80.

[147] Xing C. Clinical study on bicyclol tablets in preventing liver damage caused by anti-tuberculosis drugs. Chin J Prim Med Pharm 2013;20:16-17.

[148] Cheng L, Yang Z, Sun Z, Zhang W, Ren Y, Wang M, et al. Schizandrin $\mathrm{B}$ mitigates rifampicin-induced liver injury by inhibiting endoplasmic reticulum stress. Biol Pharm Bull 2020;43:145-52.

[149] Chen Y, Ye P, Ren C, Ren P, Ma Z, Zhang L, et al. Pharmacoeconomics of three therapeutic schemes for antituberculosis therapy induced liver injury in China. Open Med (Wars) 2018;13:53-63.

[150] Peerzada N, Renaud S, Ryan P. Vitamin C and elemental composition of some bushfruits. J Plant Nutr 1990;13:787-93.

[151] Saludes JP, Garson MJ, Franzblau SG, Aguinaldo AM. Antitubercular constituents from the hexane fraction of Morinda citrifolia Linn. (Rubiaceae). Phytother Res 2002;16:683-5.

[152] Cantrell CL, Lu T, Fronczek FR, Fischer NH, Adams LB, Franzblau SG. Antimycobacterial cycloartanes from Borrichia frutescens. J Nat Prod 1996;59:1131-6.

[153] de Sousa BC, Miguel CB, Rodrigues WF, Machado JR, da Silva MV, da Costa TA, et al. Effects of short-term consumption of 
Morinda citrifolia (noni) fruit juice on mice intestine, liver and kidney immune modulation. Food Agric Immunol 2017;28:52842.

[154] Lim SL, Goh YM, Noordin MM, Rahman HS, Othman HH, Abu Bakar NA, et al. Morinda citrifolia edible leaf extract enhanced immune response against lung cancer. Food Funct 2016;7:741-51.

[155] Ahmadi N, Mohamed S, Sulaiman Rahman H, Rosli R. Epicatechin and scopoletin-rich Morinda citrifolia leaf ameliorated leukemia via anti-inflammatory, anti-angiogenesis, and apoptosis pathways in vitro and in vivo. J Food Biochem 2019;43:e12868.

[156] Hong YH, Yi YS, Han SY, Aziz N, Kim HG, Park SH, et al. Morinda citrifolia noni water extract enhances innate and adaptive immune responses in healthy mice, ex vivo, and in vitro. Phytother Res 2019;33:676-89.

[157] Motshakeri M, Mohd Ghazali H. Nutritional, phytochemical and commercial quality of noni fruit: a multibeneficial gift from nature. Trends Food Sci Technol 2015;45:118-29.

[158] Mohamad Shalan N, Mustapha NM, Mohamed S. Morinda citrifolia leaf enhanced performance by improving angiogenesis, mitochondrial biogenesis, antioxidant, anti-inflammatory \& stress responses. Food Chem 2016;212:443-52.

[159] Damanhouri ZA, Ahmad A. A review on therapeutic potential of Piper nigrum L. (Black pepper): the King of Spices. Med Aromat Plants 2014;3:1-6.

[160] Srinivasan K. Black pepper and its pungent principle-piperine: a review of diverse physiological effects. Crit Rev Food Sci Nutr 2007;47:735-48.

[161] Khushbu C, Roshni S, Anar P, Carol M, Mayuree P. Phytochemical and therapeutic potential of Piper longum Linn a review. Int J Res Ayurveda Pharm 2011;2:157-61.

[162] Lokhande PD, Gawai KR, Kodam KM, Kuchekar BS, Chabukswar AR, Jagdale SC. Antibacterial activity of extracts of Piper longum. J Pharmacol Toxicol 2007;2:574-9.

[163] Zarai Z, Boujelbene E, Salem NB, Gargouri Y, Sayari A. Antioxidant and antimicrobial activities of various solvent extracts, piperine and piperic acid from Piper nigrum. LWT Food Sci Technol 2013;50:634-41.

[164] Murunikkara V, Pragasam SJ, Kodandaraman G, Sabina EP, Rasool M. Anti-inflammatory effect of piperine in adjuvantinduced arthritic rats-a biochemical approach. Inflammation 2012;35:1348-56.

[165] Chen S, Cheng MJ, Wu CC, Peng CF, Huang HY, Chang HS, et al. Three new phenylpropanoids from the roots of Piper taiwanense and their inhibitory activities on platelet aggregation and Mycobacterium tuberculosis. Chem Biodivers 2014;11:792-9.

[166] Diaz LE, Munoz DR, Prieto RE, Cuervo SA, Gonzalez DL, Guzman JD, et al. Antioxidant, antitubercular and cytotoxic activities of Piper imperiale. Molecules 2012;17:4142-57.

[167] Chen S, Huang HY, Cheng MJ, Wu CC, Ishikawa T, Peng CF, et al. Neolignans and phenylpropanoids from the roots of Piper taiwanense and their antiplatelet and antitubercular activities. Phytochemistry 2013;93:203-9.

[168] de L Scodro RB, Espelho SC, Agostinho Pires CT, dos S Garcia VA, Cardozo-Filho L, Cortez LER, et al. A new benzoic acid derivative from Piper diospyrifolium and its anti-Mycobacterium tuberculosis activity. Phytochem Lett 2015;11:18-23.

[169] Scodro RB, Pires CT, Carrara VS, Lemos CO, Cardozo-Filho L, Souza VA, et al. Anti-tuberculosis neolignans from Piper regnellii. Phytomedicine 2013;20:600-4.

[170] Lopes MA, Ferracioli KR, Siqueira VL, de Lima Scodro RB, Cortez DA, da Silva RZ, et al. In vitro interaction of eupomatenoid-5 from Piper solmsianum C. DC. var. solmsianum and anti-tuberculosis drugs. Int J Tuberc Lung Dis 2014;18:1513-5.

[171] Chavarria D, Silva T, Magalhães e Silva D, Remião F, Borges F. Lessons from black pepper: piperine and derivatives thereof. Expert Opin Ther Pat 2016;26:245-64.

[172] Philipova I, Valcheva V, Mihaylova R, Mateeva M, Doytchinova I, Stavrakov G. Synthetic piperine amide analogs with antimycobacterial activity. Chem Biol Drug Des 2018;91:763-8.

[173] Khan IA, Mirza ZM, Kumar A, Verma V, Qazi GN. Piperine, a phytochemical potentiator of ciprofloxacin against Staphylococcus aureus. Antimicrob Agents Chemother 2006;50:810-2.

[174] Amaral L, Martins M, Viveiros M. Enhanced killing of intracellular multidrug-resistant Mycobacterium tuberculosis by compounds that affect the activity of efflux pumps. J Antimicrob Chemother 2007;59:1237-46.

[175] Yimer EM, Tuem KB, Karim A, Ur-Rehman N, Anwar F. Nigella sativa L. (Black Cumin): a promising natural remedy for wide range of illnesses. Evid Based Complement Alternat Med 2019;2019:1528635.

[176] Randhawa MA. In vitro antituberculous activity of thymoquinone, an active principle of Nigella sativa. J Ayub Med Coll Abbottabad 2011;23:78-81.

[177] Mahmud HA, Seo H, Kim S, Islam MI, Nam KW, Cho HD, et al. Thymoquinone (TQ) inhibits the replication of intracellular Mycobacterium tuberculosis in macrophages and modulates nitric oxide production. BMC Complement Altern Med 2017;17:279.

[178] Jaswal A, Sinha N, Bhadauria M, Shrivastava S, Shukla S. Therapeutic potential of thymoquinone against anti-tuberculosis drugs induced liver damage. Environ Toxicol Pharmacol 2013;36:779-86.

[179] Jaswal A, Sharma M, Raghuvanshi S, Sharma S, Reshi MS, Uthra C, et al. Therapeutic efficacy of Nigella sativa Linn. against antituberculosis drug-induced hepatic injury in wistar rats. J Environ Pathol Toxicol Oncol 2016;35:59-71.

[180] Khudur RK, Ahmed JH. A study of the effect of Nigella sativa (Black seeds) on pyrazinamide and anti-tuberculosis drugs induced hepatotoxicity in rabbits. Int J Adv Res 2016;12:2836-45.

[181] Paul J, Nasiruddin M, Khan IA, Khan RA, Arif SH. Therapeutic effect of Nigella sativa oil in hepatotoxicity induced by isoniazid in rats. Indian J Pharm Educ Res 2019;53:242-9. 